\title{
The Carbon Price Equivalent: A Metric for Comparing Climate Change Mitigation Efforts Across Jurisdictions
}

\author{
Gabriel Weil \\ Climate Leadership Council \& Georgetown University Law Center
}

Follow this and additional works at: https://ideas.dickinsonlaw.psu.edu/dlr

Part of the Administrative Law Commons, Agency Commons, Comparative and Foreign Law Commons, Constitutional Law Commons, Energy and Utilities Law Commons, Environmental Health Commons, Environmental Law Commons, International Law Commons, Jurisdiction Commons, Jurisprudence Commons, Law and Economics Commons, Law and Politics Commons, Law and Society Commons, Legal Writing and Research Commons, Legislation Commons, Natural Resources Law Commons, Oil, Gas, and Mineral Law Commons, Science and Mathematics Education Commons, State and Local Government Law Commons, Taxation-Federal Commons, Taxation-State and Local Commons, and the Tax Law Commons

\section{Recommended Citation}

Gabriel Weil, The Carbon Price Equivalent: A Metric for Comparing Climate Change Mitigation Efforts Across Jurisdictions, 125 Dick. L. REV. 475 (2021).

Available at: https://ideas.dickinsonlaw.psu.edu/dlr/vol125/iss2/4

This Article is brought to you for free and open access by the Law Reviews at Dickinson Law IDEAS. It has been accepted for inclusion in Dickinson Law Review by an authorized editor of Dickinson Law IDEAS. For more information, please contactlja10@psu.edu. 


\title{
The Carbon Price Equivalent: A Metric for Comparing Climate Change Mitigation Efforts Across Jurisdictions
}

\author{
Gabriel Weil*
}

\section{Abstract}

Climate change presents a global commons problem: Emissions reductions on the scale needed to meet global targets do not pass a domestic cost-benefit test in most countries. To give national governments ample incentive to pursue deep decarbonization, mutual interstate coercion will be necessary. Many proposed tools of coercive climate diplomacy would require a onedimensional metric for comparing the stringency of climate change mitigation policy packages across jurisdictions. This article proposes and defends such a metric: the carbon price equivalent. There is substantial variation in the set of climate change mitigation policy instruments implemented by different countries. Nonetheless, the consequences of any combination of these policies can be summarized in terms of aggregate emissions during a specified period. Given differences in geography, resource endowments, levels of development, demographics, and other boundary conditions, aggregate emissions do not lend themselves to meaningful direct comparisons of climate change mitigation efforts. However, there will always be some carbon price that, if implemented in an otherwise neutral policy environment, would have produced this observed level of aggregate emissions during a specified period. This is the carbon price equivalent of the package of policies that produced that level of aggregate emissions. The carbon price equivalent can also be thought of as the weighted average emissions allowance trading price that would have prevailed under a cap-and-trade system

\footnotetext{
* Senior Research Associate, Climate Leadership Council. Visiting Research, Georgetown University Law Center. The views expressed in this article are my own and do not necessarily reflect those of the Climate Leadership Council or its staff. The author would like to thank Arden Rowell, Noah Kaufman, Todd Rubin, Julie Zauzmer, Matt Porterfield, Edith Brown Weiss, Bill Buzbee, Neel Sukhatme and the participants in the Georgetown Law Summer Faculty Workshop and Texas A\&M Law EnviroSchmooze for their helpful feedback and conversations.
} 
implemented in an otherwise neutral policy environment, with the cap set to match observed aggregate emissions over some period. The carbon price equivalent metric has several applications, including strategic emissions policies, strong trade linkage, and border adjustment of domestic emissions taxes and regulations. This article sets forth procedures for estimating national carbon price equivalents, including a specification of the otherwise neutral policy environment. Design issues and challenges involving currency conversions, production versus consumption emissions, spillover effects of domestic climate policies, use of a social cost of carbon to set regulatory policy, and greenhouse gases other than carbon dioxide are analyzed and resolved. A normative case for the carbon price equivalent metric is advanced in terms of both justice and efficiency. Alternative metrics are considered and found inadequate.

\section{TABle of Contents}

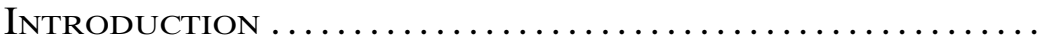

I. Basic Structure of the Carbon Price

Equivalent Metric

A. Defining an Otherwise Neutral Policy Environment...

B. Emissions Modeling Procedures and Institutions .. 484

II. Applications ..................................... 486

A. Strategic Emissions Policies ................. 487

B. Trade Linkage ......................... 488

C. Sovereign Global Climate Authority.............. 491

III. Design Issues and Challenges ................. 492

A. Use of Social Cost of Carbon in Regulatory Analysis............................... 492

B. Production Emissions or Consumption Emissions 493

C. Spillover Effects..................... 493

D. Currency Conversion..................... 495

E. GHGs Other Than Carbon Dioxide............. 498

IV. Normative Considerations .................... 509

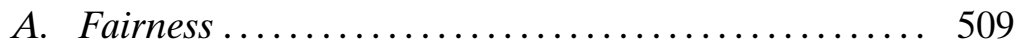

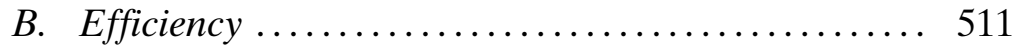

V. Technical, Political, and Legal Challenges ... 514

VI. Alternative Metrics....................... 517

A. Emissions Intensity.................... 518

B. Emission Abatement-Emission Levels versus

Future Emission Forecast .................... 519

C. Actual Carbon Prices ..................... 520

D. Implicit Carbon Prices .................. 521 
E. Energy Prices and Taxes ................... 521

F. Mitigation Costs......................... 522

G. Per Capita Emissions ......................... 523

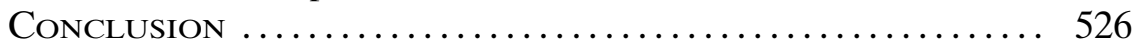

\section{INTRODUCTION}

Climate change presents a global commons problem. ${ }^{1}$ Absent international pressure, countries only have incentives to account for the domestic impacts of their emissions. More formally, they would maximize domestic welfare by internalizing the domestic social cost of carbon (SCC). The SCC is a monetary value reflecting the anticipated damage attributable to the incremental climate change induced by one marginal ton of carbon dioxide emissions. ${ }^{2}$ A country's domestic SCC only considers climate change impacts that occur within the borders of that country or otherwise directly harm that country's interests. All countries' domestic SCCs are considerably lower than the global SCC, which includes all damage attributable to an incremental ton of carbon dioxide anywhere in the world. ${ }^{3}$ If countries only internalize their domestic SCC, the global outcome will be worse for all countries than if they all internalized the global SCC. ${ }^{4}$ Accordingly, a key function of global climate change mitigation institutions should be to encourage countries to adopt emissions policies based on the global consequences of their emissions, not just the domestic consequences.

Unfortunately, the current framework for global climate change mitigation relies exclusively on voluntary and self-determined national and subnational policies for curtailing greenhouse gas (GHG) emissions. As I have argued elsewhere, this "pledge and review" model is fundamentally incapable of solving the global commons problem that climate change presents. ${ }^{5}$ If the world's nations are to successfully coordinate to prevent catastrophic climate change, more coercive mechanisms will be required. ${ }^{6}$ Most pro-

1. Kirsten H. Engel \& Scott R. Saleska, Subglobal Regulation of the Global Commons: The Case of Climate Change, 32 Ecology L.Q. 183, 184 (2005).

2. William Pizer et al., Using and Improving the Social Cost of Carbon, 346 ScI. 1189, 1189 (2014).

3. Arden Rowell, Foreign Impacts and Climate Change, 39 Harv. Env't L. REv. 371, 396 (2015).

4. Matthew J. Kotchen, Nat'l Bureau of Econ. Rsch., Which Social Cost of Carbon? A Theoretical Perspective 1 (2016), https://bit.ly/3jyMReT [https://perma.cc/PCY7-CZ96].

5. See Gabriel Weil, Incentive Compatible Climate Change Mitigation: Moving Beyond the Pledge and Review Model, 42 WM. \& Mary Env'L L. \& Pol'y Rev. 923, 927-34 (2018).

6. See id. at 934. 
posed instruments for coercive climate diplomacy require some standard measure of climate change mitigation policy stringency that can be used to compare the level of effort across jurisdictions. ${ }^{7}$

This comparison would be relatively straightforward if all jurisdictions relied on the same policy tool, such as an economy-wide carbon price. In practice, however, countries tend to adopt a complex array of policies designed to reduce GHG emissions, many of which only apply to specific industrial sectors (e.g., vehicle fuel economy standards, renewable portfolio standards). ${ }^{8}$ Many jurisdictions also adopt policies that tend to increase GHG emissions, including fossil fuel subsidies and land use regulations that encourage sprawl development and induce higher vehicles miles traveled. ${ }^{9}$ Absent a move toward centralization of climate change mitigation policy that would require a radical reconception of national sovereignty, such heterogeneity is likely to persist. ${ }^{10} \mathrm{~A}$ measure of climate policy stringency must therefore be capable of aggregating and comparing policy regimes that differ on many dimensions.

The standard approach in international climate negotiations is for countries to offer pledges in terms of percentage reductions in either aggregate emissions or emissions intensity (i.e., emissions per unit of gross domestic product (GDP)) relative to a benchmark year. ${ }^{11}$ This tends to reward jurisdictions with high historic emissions and lead to wrangling over the choice of the benchmark year. $^{12}$ It also precludes any expectation that different countries will accept the same quantitative targets, making it extremely difficult to compare levels of effort on a common scale. Keeping emissions from rising in a less developed country with low per capita

7. See id. at $936,954-55$.

8. See generally Feng An \& Amanda Sauer, Pew Ctr. on Glob. Climate Change, Comparison of Passenger Vehicle Fuel Economy and Greenhouse Gas Emission Standards Around the World (2004), https://bit.ly/ 33weJuo [https://perma.cc/D83E-9P8U]; Barry Rabe, Race to the Top: The Expanding Role of U.S. State Renewable Portfolio Standards, 7 Sustainable Dev. L. \& POL'Y 10 (2007).

9. See generally David Coady et al., Int'l Monetary Fund, Global Fossil Fuel Subsidies Remain Large: An Update Based on Country-Level Estimates (Int'l Monetary Fund, Working Paper No. 19/89, 2019), https://bit.ly/3naRSfQ [https:// perma.cc/6VAP-B7NN].

10. For a discussion of the prospect of relaxing national sovereignty in favor of a supranational climate authority, see Weil, supra note 5, at 960-63.

11. See Rosamund Pearce, Paris 2015: Tracking Country Climate Pledges, CARbON BRIEF (Feb. 6, 2017), https://bit.ly/3d4ms65 [https://perma.cc/QSJ3PNYL].

12. Countries tend to prefer selection of a benchmark year during which they had relatively high emissions. 
emissions may require greater policy effort than a 10 percent reduction in emissions in a post-industrial economy.

One alternative would be a fixed per capita GHG emissions allowance. If such an allowance were set by working backward from science-based global emissions goals (e.g., for an emissions path consistent with limiting warming to two degrees Celsius), the reductions required for high-emissions countries would be unrealistically sharp. ${ }^{13}$ In principle, this could be addressed by requiring high emissions countries to purchase emissions credits from developing countries to cover their excess emissions. In practice, however, this is probably politically and practically infeasible. ${ }^{14}$

This article analyzes and defends a more promising optionthe carbon price equivalent. This metric compares climate policies based on the degree to which they internalize the global externalities associated with GHG emissions. Economy-wide carbon taxes and cap-and-trade systems do this directly by pricing carbon emissions, but other policies like vehicle fuel economy standards and power plant emissions regulations also represent efforts, albeit implicit and uneven ones, to internalize emissions externalities. For any package of climate mitigation policies, there should be some economy-wide carbon price that could be expected to lead to the same amount of aggregate GHG emissions over any specified period. In this sense, the package of policies can be treated as equivalent to adopting an economy-wide carbon price at that level, for the purposes of international comparison, border adjustment of domestic emissions policies, and coercive diplomacy.

\section{Basic Structure of the Carbon Price Equivalent Metric}

To adopt the carbon price equivalent metric for coercive climate diplomacy, policymakers must implement a framework with two essential features. First, the framework creates a safe harbor for countries with economy-wide carbon prices, allowing them to easily avoid climate-related international sanctions simply by setting their economy-wide domestic carbon price at a sufficiently high level and refraining from adopting emissions-increasing policies that undermine their carbon price. Second, it establishes economywide carbon pricing and its attendant emissions impacts (given an otherwise neutral policy environment) as the benchmark against

13. Eric A. Posner \& Cass R. Sunstein, Should Greenhouse Gas Permits Be Allocated on a Per Capita Basis?, 97 CAL. L. Rev. 51, 89-90 (2009).

14. See id. at 52. 
which all other climate change policies will be measured. For any country that does not qualify for the safe harbor, there must be some economy-wide carbon price that will result in the observed quantity of aggregate GHG emissions over some specified period, if implemented in an otherwise neutral policy environment. This is the carbon price equivalent of that country's existing suite of climate change mitigation policies.

Another way to think of the carbon price equivalent is the allowance trading price that would prevail if an economy-wide capand-trade system were established with an emissions cap that matches the jurisdiction's actual emissions performance. That is, if policymakers had set an emissions cap at the observed quantity of aggregate GHG emissions and not implemented other emissions policies, the price at which emissions allowances would trade is the carbon price equivalent of the jurisdiction's actual package of GHG emissions policies. This conception points to a direct method of estimating the carbon price equivalent based on observed emissions. Economic models could project the weighted average emissions allowance price that would have prevailed under an economy-wide emissions trading system established in an otherwise neutral policy environment with an aggregate emissions cap set to produce the observed quantity of GHG emissions. Alternatively, retrospective emissions modeling could be used to quantify the emissions consequences of a range of economy-wide carbon tax scenarios and interpolate the level at which an economy-wide carbon price would have to be set to achieve the same emissions performance as the country's actual climate change mitigation policies. Estimating the carbon price equivalent using both of these approaches may be a useful robustness check.

In practice, this second feature would require two supporting elements: (a) a clear and unambiguous understanding of what qualifies as economy-wide carbon pricing in an otherwise neutral policy environment, and (b) a procedure for estimating the aggregate quantity of GHG emissions that a given jurisdiction would have produced had it implemented a specified economy-wide carbon price in an otherwise neutral policy environment. With these two elements in place, a country's actual emissions performance could be used to calculate its carbon price equivalent, regardless of the actual mix of policies adopted and the vigor with which they were enforced. This would ensure that the incentives coming from international pressure favor actual progress on emissions abatement. However, both of these elements raise substantial normative and technical issues. 


\section{A. Defining an Otherwise Neutral Policy Environment}

National and subnational governments implement a plethora of policies that affect GHG emissions, including production subsidies, research and development subsidies, regulations of conventional air and water pollutants, land use regulations, building codes, investments in transportation and other infrastructure, and many others. ${ }^{15}$ Many of these governmental actions are not primarily adopted as climate change mitigation policies; indeed, many induce higher GHG emissions. ${ }^{16}$

What we will call the "otherwise neutral policy environment" does not exist in any country. It is introduced as a legal fiction, to enable modeling to isolate the effects of carbon pricing and provide a benchmark against which to measure the efficacy of other policies. While defining this otherwise neutral policy environment is fraught, a few principles seem clear. First, governments that take actions that undermine the emissions reduction effects of carbon pricing should be ineligible for the safe harbor. The clearest case for this principle is fossil fuel subsidies. If a country adopts an economy-wide carbon tax, but also subsidizes oil production or gasoline consumption, it is not internalizing the GHG emissions externality at the level indicated by its headline carbon price. ${ }^{17}$ Similarly, a country implementing an economy-wide cap-and-trade system could easily inflate the price of its allowances (and thus its apparent economy-wide carbon price) at any given cap level by also subsidizing emissions-intensive coal-fired power plants. While other interventions may be less clear cut, the same basic principle should apply. For instance, governments or government-sponsored enterprises that directly operate coal-fired power plants that would not be economical under the prevailing carbon price and could not survive without government support similarly undermine the emissions impacts of carbon pricing. A similar analysis applies to agriculture subsidies, particularly with regard to emissions-intensive activities like raising cattle.

Conversely, climate change mitigation policies other than carbon pricing should also not be part of the baseline for carbon price

15. See generally Climate Change Laws of the World, Grantham Rsch. Inst. on Climate Change \& Env'T, https://bit.ly/2GkcRMT [https://perma.cc/G4NAFU47] (last visited May 18, 2019).

16. See generally Laura Merrill et al., Tackling Fossil Fuel Subsidies and Climate Change: Levelling the Energy Playing Field (2015), https:// bit.ly/33yz56r [https://perma.cc/BQQ2-5EAT].

17. Max Franks et al., Mobilizing Domestic Resources for the Agenda 2030 Via Carbon Pricing, 1 Nature Sustainability 350, 352 (2018). 
equivalent calculations. While many policies have both climate and non-climate benefits, direct regulations of GHG emissions (e.g., the Clean Power Plan in the United States) and subsidies and regulations that favor renewable energy production (e.g., wind and solar energy production tax credits, renewable electricity standards), clean vehicles (electric vehicle tax credits, vehicle GHG emissions standards), and energy efficiency (e.g., weatherization subsidies, appliance efficiency standards) are clearly not part of an otherwise neutral policy environment. Likewise, direct public investments in clean energy research, development, and deployment are non-neutral. Countries often adopt these policies in lieu of carbon pricing. The point of the carbon price equivalent metric is to provide a benchmark for the efficacy of those policies using an economy-wide carbon price as the standard. ${ }^{18}$

A somewhat more difficult set of cases involves policies with significant climate co-benefits, but that were adopted based on independent rationales. These include regulations of criteria pollutants as well as some efficiency standards that predate concerns about climate change mitigation and were adopted primarily to achieve other objectives. A maximally precise approach might seek to estimate what mix of policies each country would adopt if climate change were not a consideration. However, this would require highly contestable modeling assumptions and would be exceptionally burdensome. It is also unnecessary to achieve the core purpose of the carbon price equivalent, which is to have a neutral metric with which to compare different climate change mitigation policies in different jurisdictions. Thus, what is most important is that the otherwise neutral policy environment is defined such that it can be applied uniformly across jurisdictions. It matters less whether it has systematic errors in which all countries' carbon price equivalents are estimated to be too high or too low. The only impact this would have in relative terms is vis-a-vis countries that qualify for the economy-wide carbon price safe harbor. However, these countries could justifiably claim that their carbon price equivalent is higher than their actual carbon price if they adopt emissions-reducing policies that are not in the neutral policy baseline in addition to their economy-wide carbon price. Since the specific policies will tend to vary across jurisdictions, non-intervention should generally be treated as the neutral baseline. For instance, a policy like the United States' regulation of criteria pollutants under

18. See generally Justin Gundlach et al., Columbia Ctr. on Glob. Energy Pol'y, Interactions Between a Federal Carbon Tax and Other Climate Policies (2019), https://bit.ly/2F2HzJw. 
the Clean Air Act would not be included in the neutral policy baseline.

This principle gets more difficult to apply in other cases, however. For instance, there is strong evidence that local land use regulations that restrict density and require the construction of parking spaces induce higher vehicles miles traveled and thus higher GHG emissions. ${ }^{19}$ Similarly, national and subnational public investments in transportation infrastructure, maintenance, and operations can significantly influence emissions outcomes, depending on the allocation of resources between highway expansion, maintenance of existing roads, transit, and bicycle/pedestrian facilities. ${ }^{20}$ Should autooriented and sprawl-promoting transportation and land use policies disqualify a country from the economy-wide carbon pricing safe harbor? My inclination is to say yes, since market responses to carbon pricing in the transportation sector (e.g., living closer to work or in a transit-accessible neighborhood) may be blocked by land use regulation, thereby blunting the impact of the pricing mechanism. However, requiring completely lax zoning policies or affirmatively urbanist planning to qualify as an otherwise neutral policy environment seems extreme and likely to exclude almost all countries from the economy-wide emissions pricing safe harbor. A similar analysis applies to government investments in highways, transit, and bicycle/ pedestrian infrastructure. It is unclear what exactly would constitute a neutral policy in this domain, but transportation infrastructure investments do significantly affect GHG emissions and mediate the emissions impacts of carbon pricing.

While any definition of a climate-neutral policy environment for land use regulation, transportation infrastructure investments, and related policies like congestion pricing may be arbitrary, it will be essential to have such a benchmark to enable modelers to project the emissions path under a range of carbon pricing scenarios. The simplest option would be to treat the business as usual (BAU) policy environment in any country as its baseline for determining both safe harbor eligibility and calculating carbon price equivalents. The main drawback of this approach is that it affirmatively rewards past policies that induced higher GHG emissions by including those excess emissions in the baseline. Imagining application of this BAU-based approach to clear-cut cases like fossil fuel subsidies exposes its significant limitations. It would be a mistake to allow fossil fuel subsidies or other analogous policies in other sectors to be

19. See Alejandro E. Camacho et al., Mitigating Climate Change Through Transportation and Land Use Policy, 49 Env'T L. ReP. 10,473 (2019).

20. See id. at 10,484. 
baked into any neutral policy baseline. In sectors like transportation where there is no clear definition of a neutral policy environment, what is needed is a consistent standard that can be applied neutrally across jurisdictions, irrespective of their current policy stances. The specific content of this neutral baseline is less important than its clarity and impartiality. The lodestar for designing the carbon price equivalent metric should be enabling international coordination to promote the adoption of strong emissions reduction policies. To do so, it must be seen as legitimate by a critical mass of nations and adopted by institutions like the World Trade Organization (WTO) that will rule on the legality of coercive climate diplomacy measures.

One relevant factor in this regard is that emissions models tend not to be particularly fine-grained outside the electricity sector. ${ }^{21}$ For this reason, it may be unnecessary to specify a detailed neutral policy baseline for land use regulation and transportation infrastructure investments. What will be important is to ensure that, at whatever level of detail emissions modelers do specify background elements affecting transportation emissions, policy-sensitive parameters like land use regulation and infrastructure investments are specified equivalently for all jurisdictions for the purposes of projecting the impact of an economy-wide carbon price in an otherwise neutral policy environment. Basic differences in geography, population, and level of economic development should generally be allowed to vary across jurisdictions, even in the baseline scenario. While population growth and economic development will be affected on the margin by carbon pricing and other climate change mitigation policies, they also represent the boundary conditions that serve as essential inputs to any projection of emissions behavior.

\section{B. Emissions Modeling Procedures and Institutions}

Once a neutral policy environment is specified, the next step is to project the emissions path for a particular jurisdiction under a range of carbon pricing scenarios, assuming the policy environment is otherwise neutral. Then, if that jurisdiction declines to implement an economy-wide carbon price or does adopt measures like fossil fuel subsidies that disqualify it for the safe harbor, its emissions path can be compared to its projected emissions under an economy-wide carbon price to identify the jurisdiction's carbon

21. Interview with Noah Kaufman, Rsch. Scholar, Columbia Ctr. for Glob. Energy Pol'y (Apr. 17, 2019). 
price equivalent (which may be positive or negative) for a given period. The carbon price equivalent of the policy package adopted by a given jurisdiction is the carbon price that would have produced the same aggregate GHG emissions over a specified period, if implemented in an otherwise neutral policy environment as described above. Alternatively, the carbon price equivalent can be directly estimated by imagining an emissions trading system had been adopted (again in an otherwise neutral policy environment) with a cap set to match the country's observed emissions performance and projecting the weighted average price that emissions permits have sold for.

In principle, either projected emissions under a specified policy regime or actual emissions could be used to calculate a jurisdiction's carbon price equivalent. The benefit of using projected emissions is that this would eliminate the influence of exogenous shocks (a recession, unanticipated changes in the relative prices of energy sources, etc.) on the apparent level of climate change mitigation effort. However, using projected emissions to identify the carbon price equivalent would require both granular, up-front specificity regarding the package of national and subnational policies to be implemented and a high level of confidence in successful implementation and enforcement of those policies. It would also enable jurisdictions to declare ambitious emissions policies that would score as highly effective in prospective modeling, but then use lax enforcement to avoid the economic and political costs of such actions.

A better response to the problem of exogenous shocks would be to rerun models of the impact of carbon pricing retrospectively, incorporating information about any relevant shocks, to determine a jurisdiction's carbon price equivalent for a given period. The main drawback of this approach is that a jurisdiction's carbon price equivalent could only ever be known in retrospect, which would complicate its use in coercive climate diplomacy. This lag would be manageable, however, if carbon price equivalent estimates were updated regularly, perhaps on an annual basis.

At least initially, carbon price equivalent estimates are likely to be proposed unilaterally by countries seeking to adopt border adjusted emissions policies or other coercive climate diplomacy measures. For unilateral strategic emissions policies (see Part II(a) below), no external authority would need to validate the process used to calculate carbon price equivalents. ${ }^{22}$ However, if the juris-

22. I.e., any country that decides to index its carbon tax to a measure of the weighted average global carbon price equivalent could use whatever procedure it desires to estimate that metric. 
diction wants its strategic emissions policies to actually influence the mitigation efforts of other jurisdictions, it will need to be transparent about its methods and ensure that its metric is actually sensitive to changes in mitigation effort. For border adjustments and other policies that interact with existing bodies of international law, the WTO and other international institutions will be charged with certifying these estimates and developing a body of jurisprudence and best practices for calculating carbon price equivalents. ${ }^{23}$

Ultimately, it would be preferable to move toward a situation where the emissions modeling required to estimate carbon price equivalents is conducted by impartial officials at international institutions that oversee climate diplomacy. Inevitably, divergences between emissions models will take on greater salience and controversy when concrete financial stakes are attached to their projections. Governments that do not adopt economy-wide carbon pricing will have ample incentive to adopt models that suggest carbon pricing would have limited emissions impacts in their jurisdictions in order to minimize the level of mitigation effort needed to achieve a given carbon price equivalent. Governments that do adopt economy-wide carbon pricing, by contrast, will tend to favor models with high price elasticity of GHG emissions. All countries will be tempted to favor models that suggest local conditions in their jurisdictions produce particularly low elasticity of demand for carbon-intensive goods and services, reducing the expected impact of carbon pricing on aggregate emissions. These incentives underscore the need for an independent body of experts to certify GHG emissions models as suitable for use in estimating carbon price equivalents.

\section{Applications}

The carbon price equivalent metric has several potential applications. The most straightforward application is simply to compare climate change mitigation commitments and performance within the existing pledge and review framework. A key premise of this framework is the efficacy of "shaming" countries that refuse to take sufficient measures to curtail their GHG emissions. ${ }^{24}$ Comparing a country's carbon price equivalent to an estimate of the global SCC would provide a quantitative measure of the extent to which that

23. For a detailed discussion of the permissibility of border adjustments under international trade law, see Weil, supra note 5, at 947-55.

24. See generally Behnam Taebi \& Azar Safari, On Effectiveness and Legitimacy of 'Shaming' as a Strategy for Combatting Climate Change, 23 SCI. \& ENG'G ETHics 1289 (2017). 
country is shirking its shared responsibility to protect the global commons.

More ambitiously, the carbon price equivalent could be used to support many of the coercive climate diplomacy mechanisms I analyzed in a previous article. ${ }^{25}$ These mechanisms include strategic emissions abatement policies, trade linkage, and creation of a supranational climate change mitigation authority. ${ }^{26}$

\section{A. Strategic Emissions Policies}

One form of strategic emissions abatement policy would entail one or more jurisdictions explicitly linking the stringency of their domestic emissions policies to an index of the stringency of policies adopted throughout the rest of the world. For instance, a country could adopt an economy-wide carbon tax that scales automatically with-but does not necessarily match-the weighted average carbon price or carbon price equivalent prevailing throughout the rest of the world. This would give other governments some additional incentive to increase the stringency of their own mitigation policies, by giving them some leverage over the policies of others and thus making the domestic cost-benefit calculus favor somewhat more ambitious policies. Without a viable carbon price equivalent metric, this policy would be basically unworkable, as it requires some one-dimensional metric of global mitigation policy stringency as an input. On its own, however, this form of strategic emissions abatement policy is probably too weak and diffuse to fundamentally alter the calculus facing other nations. ${ }^{27}$

One proposal to increase the strategic leverage of conditional abatement policies is to form a top-down grand coalition where all countries adopt a globally optimal carbon price or carbon price equivalent if and only if all other countries join the coalition. ${ }^{28}$ If any country defects, the coalition would dissolve and all countries would revert to their (much lower) domestically optimal carbon prices, failing to account for the negative effects of domestic GHG emissions on other countries. If the commitment to dissolve the coalition in response to a single defection is credible, this structure can be shown to produce optimal emissions reductions given other-

25. See generally Weil, supra note 5.

26. See generally id.

27. See id. at 937.

28. Peter John Wood, Climate Change and Game Theory: A Mathematical Survey, Env't Econ. Rsch. Hub 1, 20 (May 5, 2010), http://bit.ly/3oMM1yn [https://perma.cc/2X3D-D9NC]. 
wise reasonable assumptions. ${ }^{29}$ In theory, this approach could be adopted without the carbon price equivalent metric, by simply requiring that all countries actually adopt the globally optimal economy-wide carbon price (and refrain from undermining it with other policies like fossil fuel subsidies), but this would impose a significant additional barrier to participation and lower the odds of success.

Intermediate approaches based on bottom-up coalitions are also possible. If several countries agree to adopt carbon price equivalents that maximize their joint welfare, the coalition's optimal carbon price equivalent will rise in proportion to the share of global emissions contained within the coalition. ${ }^{30}$ The coalition's optimal carbon price equivalent approaches the globally optimal carbon price as the coalition expands to include all countries. As with a top-down coalition, this approach could in principle be adopted without a carbon price equivalent metric by requiring actual implementation of economy-wide carbon pricing by all members. Once again, this would make coalition membership less attractive for some potential participants that wish to rely primarily on non-pricing policies and would undermine the overall mitigation benefits.

\section{B. Trade Linkage}

The carbon price equivalent metric could also be used to implement trade linkage, a tool that enables more targeted incentives than strategic emissions policies. ${ }^{31}$ Trade linkage options fall into two broad categories, weak and strong. Weak trade linkage, often referred to as carbon tariffs or border tax adjustments, entails charging importers a fee reflecting the GHG emissions associated with the production and transport of the imported goods. ${ }^{32}$ In the simplest case, a domestic carbon tax could be border adjusted (applied to imports) so as not to discriminate between domestic and foreign production. Indeed, most carbon tax proposals for the United States include border adjustment provisions. ${ }^{33}$ However, none of these proposals specifies a mechanism for determining how border adjustments should be calculated to account for non-pricing

29. Id. at 21.

30. William Nordhaus, Climate Clubs: Overcoming Free-Riding in International Climate Policy, 105 Am. Econ. Rev. 1339, 1345 (2015).

31. See Weil, supra note 5, at 939-57.

32. Id. at 944.

33. Adele C. Morris, Urban-Brookings Tax Pol'y Ctr., Making Border Carbon Adjustments Work in Law and Practice 8 (2018), https:// brook.gs/2GC8LQf [https://perma.cc/Q8HJ-V7RF]. 
policies in other jurisdictions. For instance, the American Opportunity Carbon Fee Act of 2018 would impose an "equivalency fee" on imports of energy-intensive manufactured goods and authorize a refund of the cost of the domestic fee for exported energy-intensive manufactured goods. ${ }^{34}$ Both the equivalency fee on imports and the refund on exports are to be reduced by the amount of fees that would be imposed on comparable energy-intensive goods in the exporting/importing country. The bill further instructs the Secretary of the Treasury to establish regulations under which "foreign policies that have substantially the same effect in reducing emissions of greenhouse gases as fees shall be treated as fees" for the purposes of reductions in border adjustments. ${ }^{35}$

The carbon price equivalent is precisely the metric needed to calculate border adjustments for exporting/importing countries that use policies other than carbon pricing to drive reductions in GHG emissions. Moreover, this situation is the rule, not some rare exception; most countries do not rely primarily on economy-wide carbon pricing to reduce GHG emissions, and no country relies exclusively on this policy tool. ${ }^{36}$ To avoid double-taxation/regulation of embedded emissions and maintain compliance with international trade law, border adjustment calculations will require some measure of the stringency of regulation that imported goods were subject to in the exporting jurisdiction. ${ }^{37}$ The carbon price equivalent metric neatly fills this gap, allowing climate change mitigation policy stringency to be measured on a single dimension that can be readily translated into a border adjustment. Once the metric is fully developed and applied to any set of two countries, moreover, it would enable countries to border adjust any package of emissions reduction policies, using the difference between the carbon price equivalents of the exporting country's policy regimes. ${ }^{38}$

34. American Opportunity Carbon Fee Act of 2018, S. 2368, 115th Cong. $\S 4695$ (b)-(c) (2018), https://bit.ly/30HbuhX [https://perma.cc/2MVU-LSSN].

35. Id. $\$ 4695(\mathrm{~d})$.

36. See Carbon Pricing Dashboard, The World BAnK, https://bit.ly/2SCaoj7 [https://perma.cc/DE94-TKXM] (last visited May 18, 2019).

37. See Weil, supra note 5, at 954-55. But see Matthew C. Porterfield, Border Adjustments for Carbon Taxes, PPMs, and the WTO, 41 U. PA. J. InT'L L. 1, 7 (2019) (arguing that carbon taxes can be border adjusted under the GATT without recourse to Article XX's environmental exception, negating the need to satisfy the Chapeau).

38. A potential objection to using the carbon price equivalent to set border adjustments is that the policies driving emissions reductions in a particular jurisdiction may not be applied equally to tradable goods. In the simplest case, a country could apply a high carbon tax on generation of grid electricity and transportation fuels but exclude all manufacturing of goods that compete with imports or are produced for export. Under the carbon price equivalent approach, other countries 
Strong trade linkage would apply across-the-board tariffs to all imports from countries that fall short of some threshold of climate policy stringency. In William Nordhaus's Climate Club proposal, all countries that wish to join the club would have to agree to set a minimum carbon price and apply across-the-board tariff increases of five to ten percent to all imports from non-club countries. ${ }^{39}$ Nordhaus's proposal would require that all club members actually adopt economy-wide carbon pricing as their primary climate change mitigation instrument and make it the only instrument they can take credit for in the international arena. ${ }^{40}$ It would also have a sharp cutoff, such that the same tariff rate is applied to all non-club member countries, regardless of the stringency of their GHG emissions policies. As specified by Nordhaus, therefore, this proposal would not require a metric of policy stringency other than actual economy-wide carbon prices. ${ }^{41}$

Other forms of strong trade linkage, including tweaked versions of Nordhaus's Carbon Club proposal, would require a more comprehensive and flexible metric. Even if committed to requiring all countries to adopt economy-wide carbon pricing at a minimum threshold price in order to avoid across-the-board tariffs on their exports and to refusing to scale those tariffs in proportion to the shortfall in countries' climate mitigation effort, a Carbon Club would not want to allow its members to undermine the mitigation

could not border adjust their full domestic carbon prices on imports from that country. This would prevent border adjustment from fulfilling its core economic rationale of avoiding distortion of production patterns due to differences across jurisdictions. However, it would maintain the political incentive for countries to implement strong domestic emissions policies. Moreover, to the extent that a jurisdiction is successful in boosting its net exports of emissions-intensive goods by pursuing a domestic mitigation framework that favors tradable sectors, this will lead its domestic emissions to rise. This will result in some combination of a higher carbon price equivalent (which would make the economic distortion self-limiting) and the need for even higher carbon prices or other emissions regulations in nontradable sectors to maintain a competitive carbon price equivalent. In either case, the domestic benefits to the country pursuing this strategy would be dubious. The same basic logic applies if a country with strong emissions policies for non-tradable sectors seeks to "border adjust" those policies on imports. This would be somewhat economically distortionary, since it would apply a tax to imports that compete with domestic goods that are not subject to comparable carbon prices or other emissions regulations. But this distortion would be inherently self-limiting and the underlying strategy would not produce net domestic benefits for the country creating the distortion. For the international trade system to avoid this potential distortion, it would have to require border adjustment to be based on the policies that actually apply to the particular goods in question. Aggregate national emissions could not be used to summarize these policies.

39. Nordhaus, supra note 30, at 1345.

40. $I d$.

41. See id. 
benefits of the headline carbon price by instituting offsetting policies like fossil fuel production or consumption subsidies. This would require articulation of an otherwise neutral policy environment and of the amount that the minimum economy-wide carbon price for a club member would be raised or lowered based on deviations from neutrality. Further modifications of Nordhaus's proposal could include allowing countries to qualify for club membership based on higher carbon price that are not fully economy-wide (e.g., imperfectly enforced or exempting some sectors or sources); allowing qualification for club membership based in part or entirely on policies other than carbon pricing; and scaling of across-theboard tariffs with the margin by which non-club countries fail to qualify for membership. Each of these measures would require some means of mathematically comparing different climate change mitigation policies.

\section{Sovereign Global Climate Authority}

Even under a hypothetical sovereign global climate authority, a carbon price equivalent may be necessary. The strongest form of such a global authority would directly implement a global mitigation policy, such as a globally harmonized carbon price. However, the semi-strong and weak versions would retain substantial national policy flexibility and thus require a metric for comparing mitigation regimes. A semi-strong global climate authority would set an emissions target for each country and allow national discretion with regard to the means of meeting the target..$^{42}$ The authority would only intervene to directly regulate emissions in countries that fail to meet their emissions targets. ${ }^{43}$ This process could function similarly to cooperative federalism in the United States, where the Environmental Protection Agency has authority to impose Federal Implementation Plans on states that fail to meet their obligations under the Clean Air Act. ${ }^{44}$ In setting the emissions requirements for each country, the carbon price equivalent would offer a principled basis on which to allocate the climate change mitigation burden. A weak version of the global climate authority would never directly intervene to regulate emissions, but merely set emissions requirements and then authorize retaliation (trade sanctions, other coordinated forms of issue linkage) against countries that fail to meet their emis-

42. See Weil, supra note 5 , at 962.

43. Id.

44. Holly Doremus \& W. Michael Hanemann, Of Babies and Bathwater: Why the Clean Air Act's Cooperative Federalism Framework Is Useful for Addressing Global Warming, 50 ARIz. L. Rev. 799, 818 (2008). 
sions obligations..$^{45}$ Once again, this would require some standard against which to measure national emissions performance, which the carbon price equivalent would provide.

\section{Design Issues And Challenges}

\section{A. Use of Social Cost of Carbon in Regulatory Analysis}

Recall that the social cost of carbon (SCC) is an estimate of the marginal damage produced by a ton of carbon dioxide. ${ }^{46}$ In the United States and other jurisdictions, an official SCC estimate is used as an analysis tool to evaluate policies that affect GHG emissions. ${ }^{47}$ One might argue that countries that use an SCC to set emissions regulations should be afforded the same safe harbor as countries that adopt economy-wide emissions pricing. This would be a mistake. A regulatory SCC cannot be treated as equivalent to an economy-wide carbon price because a regulatory SCC has a narrower scope of applicability. At least under existing practice in the United States, a regulatory SCC only comes into play when considering enactment of a regulation with an independent basis in law. ${ }^{48}$ While the use of an SCC will tend to make regulations that reduce GHG emissions more likely to pass a cost-benefit test and militate in favor of more stringent GHG regulations, it cannot be expected to have the same pervasive impact as an economy-wide carbon price set at the same level. ${ }^{49}$ It is likely that many economic activities that would not be undertaken if subject to a $\$ 30$ per ton carbon tax would continue under a regulatory regime based on a $\$ 30$ per ton SCC. Individual consumption behavior in particular is unlikely to be reached as effectively by a regulatory regime based on an SCC but would be affected by a carbon tax. Accordingly, as for other approaches that deviate from economy-wide carbon pricing, it will be necessary to use economic models to translate the aggregate emissions levels to their carbon price equivalent as outlined above.

45. Weil, supra note 5, at 962.

46. The Social Cost of Carbon: Estimating the Benefits of Reducing Greenhouse Gas Emissions, U.S. Env'T РRot. AgenCy, https://bit.ly/30LnrUa [https:// perma.cc/J89S-SF54] (last visited May 29, 2019).

47. Id.

48. Noah Kaufman, The Use of Current Social Cost of Carbon Estimates in Taxes and Subsidies, Columbia Ctr. on Glob. Energy Pol'y 3 (Mar. 27, 2018), http://bit.ly/3ntvezu [https://perma.cc/SPU4-T85B].

49. Id. 


\section{B. Production Emissions or Consumption Emissions}

Another consideration is how to allocate responsibility for GHGs emitted, often in long supply chains that cross international borders, in the production of tradable goods. There is a credible case to be made that responsibility for these emissions should lie primarily with the consumers of final products with embedded GHG emissions, rather than with the producers. ${ }^{50}$ Regardless of the proper normative allocation of responsibility, however, it is clear that the carbon price equivalent metric should be based on emissions that actually occur within the jurisdiction.

There are three reasons for this. First, the primary regulatory tools available to jurisdictions are best suited to control of emissions that occur within or have a direct nexus with the jurisdiction's geographic boundaries (e.g., in the case of shipping emissions that occur mostly in international waters but use fuel purchased within some jurisdiction's port). ${ }^{51}$ Second, one of the core functions of the carbon price equivalent metric is to enable jurisdictions to effectively shift the locus of emissions regulations from domestic production to domestic consumption via border adjustments. For the metric to serve this function, the balance of the domestic emissions regime must be evaluated on the basis of its effects on the producers operating under that regime. Finally, a significant portion of the costs of emissions abatement regulations, including carbon prices, will tend to be passed along to the final consumers of carbon intensive goods and services, regardless of the formal legal incidence. ${ }^{52}$

\section{Spillover Effects}

Some climate change mitigation policies are designed to noncoercively induce decreases in foreign GHG emissions. In particular, research and development (R\&D) subsidies for clean technologies are often intended to make cleaner sources of energy more cost competitive everywhere, not just in the domestic market. ${ }^{53}$ In fact,

50. Karl Steininger et. al., Justice and Cost Effectiveness of ConsumptionBased Versus Production-Based Approaches in the Case of Unilateral Climate Policies, 24 Glob. Env't. Change 75, 75 (2014).

51. See id.

52. See e.g., Kevin A. Hassett, Aparna Mathur \& Gilbert E. Metcalf, The Incidence of a U.S. Carbon Tax: A Lifetime and Regional Analysis, 30 ENERGY J. 155, 161 (2007).

53. E.g., Knut Einar Rosendahl, Cost-Effective Environmental Policy: Implications of Induced Technological Change, 48 J. Env'T. Econ. \& Mgmt. 1099, 1107 (2004); Valentina Bosetti et al., What Should We Expect From Innovation? A Model-Based Assessment of the Environmental and Mitigation Cost Implications of Climate-Related R\&D, 33 EnERGy ECON. 1313, 1313 (2011). 
some scholars argue that technological breakthroughs in clean energy are the only viable path to avoiding climate catastrophe, given the daunting obstacles to international coordination on emissions reduction. ${ }^{54}$ Without resolving that question, we can recognize circumstances under which a country's domestic emissions path may not fully capture their level of climate change mitigation effort. This may be true on the downside as well as the upside. Not all technological breakthroughs will induce lower GHG emissions. ${ }^{55}$ Some, like advances in hydraulic fracturing, have ambiguous net emissions impact, depending on the extent to which cheaper natural gas displaces coal on the one hand or renewables on the other. ${ }^{56}$ Technologies that induce increased demand for energy, transportation, meat, or carbon-intensive materials will be unambiguously counterproductive to climate change mitigation. ${ }^{57}$ Importantly, the emissions impacts of all these technological improvements need not occur exclusively or even primarily in the countries where they are developed. If $\mathrm{R} \& \mathrm{D}$ for low-carbon technology were a purely private sector phenomenon, perhaps we could safely ignore these spillovers. To the extent that governments are actively encouraging or even funding this $\mathrm{R} \& \mathrm{D}$, however, emissions performance may be a poor measure of policy ambition.

At the outset, it should be noted that any plausible metric for comparing the level of effort across jurisdictions will face the same problem in accounting for spillover effects. Neither aggregate emissions relative to a benchmark year, per capita emissions, nor emissions intensity account for spillovers. Cost-based measures of effort could theoretically account for R\&D subsidies but would allow countries to claim expenditures as climate mitigation investments even when pursued for other reasons and producing little to no emissions results. Tracing the extraterritorial emissions effects of R\&D subsidies would be necessarily speculative and contentious, potentially undermining the legitimacy of a mitigation effort metric.

The case for the need to count emissions spillovers rests on a key premise: that clean energy $\mathrm{R} \& \mathrm{D}$ is a global public good. In

54. Noah Smith, What Can We Do to Put a Stop to Global Warming?, NoAhPINION (Feb. 1, 2013), https://bit.ly/30VJjfF [https://perma.cc/A2DU-ZU8F].

55. See Antoine Dechezleprêtre, Ralf Martin \& Myra Mohnen, Knowledge Spillovers From Clean and Dirty Technologies 2 (Grantham Rsch. Inst. on Climate Change \& the Env't, Working Paper No. 135, 2017).

56. See Douglas Arent et al., A Review of Water and Greenhouse Gas Impacts of Unconventional Natural Gas Development in the United States, 2 MRS ENERGY \& Sustainability E4, 18 (2015).

57. See generally Christoph Weber \& Adriaan Perrels, Modelling Lifestyle Effects on Energy Demand and Related Emissions, 28 ENERGY POL'y 549 (2000). 
economic terms, a public good is both non-excludable and non-rival. ${ }^{58}$ Non-excludable means non-payers cannot be kept from enjoying the benefits of the good at a reasonable cost. ${ }^{59}$ Non-rival means one person's enjoyment does not interfere with the simultaneous enjoyment of the good by other people. ${ }^{60}$ Technological advances do tend to be non-rival. ${ }^{61}$ Given the existence of the global intellectual property regime, however, they are excludable to a significant extent. Arguably, this means that technological innovation is more a club good (excludable, but non-rival) than a public good. ${ }^{62}$ Perhaps countries could foster greater emissions reductions by declining to enforce their intellectual property claims or licensing technologies at below profit-maximizing prices. To the extent this is the case, however, there are likely to be similar potential efficiency gains in promoting broader sharing of intellectual property outside the context of climate mitigation. If this does represent a global market or policy failure, it is one with only an incidental nexus with climate change mitigation and should be addressed on its own terms. Accordingly, clean energy $R \& D$ does not pose a distinct public goods problem, and thus the carbon price equivalent metric need not take account for emissions spillover effects.

\section{Currency Conversion}

The use of a monetized figure like the carbon price equivalent to make comparisons across jurisdictions is often complicated by those jurisdictions' use of different local currencies. There are two different ways to convert between currencies: market exchange rates and purchasing power parity (PPP) exchange rates. ${ }^{63}$ Market exchange rates are simply the prevailing price at which one currency is exchanged for another on foreign exchange markets. Market exchange rates, while often volatile, are readily observable. PPP exchange rates are based on the rate at which one currency

58. Tyler Cowen, Public Goods, Concise Encyclopedia of Economics, The Libr. of Econs. \& Liberty, https://bit.ly/3iBr4C5 [https://perma.cc/T3SM-FCNN] (last visited May 26, 2019).

59. Id.

60. Id.

61. See Reed College, Case of the Day: Appropriability and Incentives for Innovation, https://bit.ly/30F8geQ [https://perma.cc/B4MZ-6FTL] (last visited May 27, 2019).

62. See George Alogoskoufis, Lecture Slides: 6. Public Goods, Common Resources and Club Goods, TuFTs UnIV. (Jan. 28, 2019), https://bit.ly/3lqKgV1 [https://perma.cc/6AGX-4PKJ].

63. Joseph E. Aldy \& William A. Pizer, Alternative Metrics for Comparing Domestic Climate Change Mitigation Efforts and the Emerging International Climate Policy Architecture, 14 R. Env'T ECONs. \& POL'y 3, 9 (2014). 
would have to be converted into another to buy the same amount of goods and services. ${ }^{64}$ As a stylized example, if a hamburger of a certain quality sells for $£ 2$ in London and $\$ 4$ in New York, that would imply a PPP exchange rate of 1 English pound to 2 U.S. dollars. Since relative prices vary across economies, prices of a large basket of goods are needed to calculate PPP exchange rates. The International Comparison Program, created by the United Nations and the University of Pennsylvania and administered by the World Bank, calculates PPP exchange rates for 147 countries based on a global survey of national average prices for approximately 1,000 closely specified products. ${ }^{65}$ Significant divergences between PPP and market exchange rates tend to emerge between higher and lower wage countries. While the prices of tradable manufactured goods tend to converge across economies, labor-intensive non-tradable services like haircuts tend to be more expensive in high-wage economies. For instance, the market exchange rate between U.S. dollars and Chinese yuan in 2017 ranged from 6.49 to 6.96 yuan per dollar, ${ }^{66}$ whereas the PPP exchange rate was only 3.55 yuan per dollar. ${ }^{67}$

Which exchange rate should be used to compare carbon prices and carbon price equivalents? While PPP exchange rates are informative and useful for certain purposes, such as comparing real incomes across economies, market exchange rates are the most relevant when considering international financial flows. ${ }^{68}$ Since GHG emissions externalities are analogous to financial flows, market exchange rates should be used for carbon price equivalent currency conversions. To see why, consider what the carbon price equivalent seeks to approximate: a globally harmonized carbon price. In particular, imagine a global cap-and-trade system with allowances that are tradable across all national borders. Under such a system, emissions abatement would tend to occur in locations where it is least costly. If emitters in a particular country have few low-cost abatement opportunities, they will purchase allowances from foreign entities with lower abatement costs. If those two countries have different currencies, the transaction will necessarily occur at market

64. Tim Callen, Purchasing Power Parity: Weights Matter, InT'L Monetary Fund (Feb. 24, 2020), https://bit.ly/2Sz6EyZ [https://perma.cc/4H87-AD29].

65. International Comparison Program (ICP), The World BANK, https:// bit.ly/36I9UAm [https://perma.cc/L6FX-DCSY] (last visited May 19, 2019).

66. Dollar Yuan Exchange Rate-35 Year Historical Chart, Macrotrends, https://bit.ly/33EJ3mY [https://perma.cc/8XHS-3STT] (last visited May 23, 2019).

67. Purchasing Power Parities (PPP), Org. FOR Econ. CoOp. \& Dev., https:/ /bit.ly/34us3yS [https://perma.cc/E8CT-2W69] (last visited May 22, 2019).

68. Aldy \& Pizer, supra note 63, at 11. 
exchange rates. That is, what it means for there to be a lower-cost abatement opportunity in China than in the United States is precisely that a Chinese allowance holder should be willing to sell allowances to an American emitter for a price in U.S. dollars that is less than the abatement cost for the American emitter. But the Chinese allowance holder will only be willing to do so if the quantity of Chinese yuan the sale yields is greater than its marginal abatement cost. To the extent that lower labor costs render marginal emissions abatement cheaper in some countries than in others, that is not something that should be adjusted away with a PPP exchange rate. It is an economic reality that should drive where marginal abatement occurs. Another way to think of this is in terms of how efficient compensation for the global externalities caused by GHG emissions would function. If a global carbon tax internalized a global estimate of the SCC and distributed the funds it raised to parties in proportion to their exposure to climate impacts, the tax rate would have to be adjusted using market exchange rates to provide proper compensation. The quantity of local goods and services that could be purchased with those funds in the emitting country would be of no relevance to the recipients of those funds in other countries.

In both cases, of course, one can rightly object that no international compensation for ongoing-or historic-emissions is actually provided for under the carbon price equivalent approach. In practice then, using market exchange rates to convert carbon price equivalents just means that developing countries will bear a larger proportion of the mitigation burden or else be punished via coercive climate diplomacy measures for failing to do so. This is a valid criticism. As I will argue below, however, this injustice is largely a function of the fundamental power dynamics and incentives at work in the geopolitics of climate change. Countries with limited exposure to climate impacts and few low-cost opportunities to reduce their emissions should indeed offer compensation to countries that are particularly exposed to climate change impacts and/or have many low-cost emissions abatement opportunities. Unfortunately, they lack any real incentive to do so. The carbon price equivalent approach is a tool designed to help overcome the global commons problem, but it cannot transform the fundamental forces at play. From a normative perspective, the carbon price equivalent embodies the principle that everyone, everywhere, should be responsible for paying the full social cost of their GHG emission-intensive activities. Carried through to its logical conclusion, this principle would require that compensation occur. The fact that such com- 
pensation is unlikely to occur indeed reflects poorly on those who will continue to impose emissions externalities on their poorer neighbors. However, this is an analytically distinct issue and not a compelling argument for using economically distortionary PPP exchange rates.

To see why using PPP exchange rates would be distortionary, consider a small, open economy that devalues its currency. In the short term, local prices for tradable goods (imports and exportable goods produced locally) will tend to rise sharply in terms of the local currency but remain fairly stable in terms of foreign currencies. ${ }^{69}$ The price of non-tradable goods and services will tend to rise only modestly in terms of the local currency and fall fairly sharply in terms of foreign currencies. ${ }^{70}$ Accordingly, the fall in the PPP exchange rate will be significantly less than the fall in the market exchange rate. ${ }^{71}$ This translates into a fall in local wages relative to the cost of imports and in terms of foreign currencies, even though nominal wages may rise modestly. ${ }^{72}$ To the extent that the real resource costs of marginal GHG emissions abatement are tradable goods, using market exchange rates would leave the pattern of abatement unchanged by currency devaluation. Using PPP exchange rates would shift mitigation effort to other jurisdictions with slightly higher real marginal abatement costs. To the extent that abatement effort comes in the form of labor costs, the devaluation genuinely makes the local labor less costly and so should result in a marginal increase in local abatement effort. This shift would only occur using market exchange rates. PPP exchange rates would cancel out the effect of declining real labor costs, preventing the currency devaluation from shifting abatement patterns. In both cases, using market exchange rates tends to equalize the real marginal abatement cost across jurisdictions that adopt a uniform carbon price.

\section{E. GHGs Other Than Carbon Dioxide}

Carbon dioxide is not the only GHG. Other GHGs, including methane, nitrous oxide, and several fluorinated gases, account for approximately 37 percent of historic anthropogenic climate

69. Ariel Burstein, Martin Eichenbaum \& Sergio Rebelo, Large Devaluations and the Real Exchange Rate, 113 J. PoL. ECon. 742, 743 (2005).

70. Id. at 742 .

71. Id. at 744 .

72. Id. 
change. ${ }^{73}$ Moreover, mitigation strategies that limit emissions of multiple GHGs could produce up to 40 percent in compliance cost savings, relative to regulations limiting only carbon dioxide and targeting similar climate outcomes. ${ }^{74}$ Both the potency and the atmospheric lifetimes of GHGs vary widely. ${ }^{75}$ These two dimensions are typically compressed into a single relative measure of global warming potential (GWP). GWP is based on a linear scale, with the GWP of carbon dioxide defined to be 1. The GWP of all other GHGs is the ratio of the amount of heat trapped by one ton of the gas to that captured by one ton of carbon dioxide over a given time period. ${ }^{76}$ The GWP for a gas depends on the quantity and frequency of radiation it absorbs, which combine to determine its radiative forcing and its atmospheric lifetime. ${ }^{77}$ GWP values can be used to calculate the carbon dioxide equivalent $\left(\mathrm{CO}_{2 \mathrm{e}}\right)$ for any mix of GHGs.

In principle, the carbon price equivalent approach could be generalized to a GHG price equivalent. Full GHG pricing would not only be economy-wide in terms of sources but also cover all significant GHGs and apply a price equal to the per-ton carbon price multiplied by the GWP of each GHG. Another way to think of this is that both the carbon price and aggregate national emissions in any given time period would be applied to $\mathrm{CO}_{2 \mathrm{e}}$ rather than $\mathrm{CO}_{2}$. Contrary to widespread assumptions in climate policy circles, however, there is not one unique GWP value for any given $\mathrm{GHG}-$ other than carbon dioxide, which serves as the reference gas. Rather, the GWP value for any particular gas depends on the time interval over which the heat-trapping effects are considered. ${ }^{78}$ Common time intervals used for calculating GWP are 20, 50, and 100 years, with 100 years treated as the standard. ${ }^{79}$ Use of shorter

73. Why Does CO2 Get Most of the Attention When There Are So Many Other Heat-Trapping Gases?, Union of Concerned Scientists (Aug. 3, 2017), https:// bit.ly/31r9Hpn [https://perma.cc/96K4-E7GQ].

74. Detlef P. van Vuuren, John Weyant \& Francisco de la Chesnaye, MultiGas Scenarios to Stabilize Radiative Forcing, 28 EnERGy Econ. 102, 113 (2006).

75. See Why Does CO2 Get Most of the Attention When There Are So Many Other Heat-Trapping Gases?, supra note 73.

76. Greenhouse Gas Emissions: Understanding Global Warming Potentials, Env't Prot. Agency, https://bit.ly/3nsejNH [https://perma.cc/TSM4-8NXB] (last visited June 8, 2019).

77. $I d$.

78. Odd Godal \& Jan Fuglestvedt, Testing 100-Year Global Warming Potentials: Impacts on Compliance Costs and Abatement Profile, 52 Climactic Change 93, 93 (2002).

79. Mark E. Brennan and Benjamin F. Zaitchik, On the Potential for Alternative Greenhouse Gas Equivalence Metrics to Influence Sectoral Mitigation Patterns, Env'T. Rsch. LetTers, Jan.-Mar. 2013, at 1, 2. 
time intervals will tend to give higher GWP values for short-lived gases like methane (12.2 year lifetime), which has an estimated GWP of 56 for a 20 -year horizon, but only 21 for a 100 -year horizon and 5.6 for a 500 -year horizon. Long-lived gases like sulfur hexafluoride (3,200 year lifetime) show the opposite effect, with an estimated GWP of 16,300 for a 20-year horizon rising to 23,900 for a 100-year horizon and 34,900 for 500 years. ${ }^{80}$ This "rectangular" time horizon approach weights all years within the horizon equally, with the weight falling off abruptly to zero beyond it. ${ }^{81}$

GWP is calculated by taking the integral of the radiative forcing induced by instantaneous release of one kilogram of a gas over the selected time horizon and dividing it by the radiative forcing that results from the instantaneous release of one kilogram of carbon dioxide integrated over the same time horizon. ${ }^{82}$ Radiative forcing is the net change in the earth's energy balance induced by a given perturbation. The instantaneous radiative forcing, which serves as the function integrated over to calculate GWP, is the instantaneous change in net radiative flux, usually expressed in watts per square meter. This conception of GWP was introduced in 1990 by the Intergovernmental Panel on Climate Change's (IPCC) first assessment. The 1997 Kyoto Protocol adopted the 100-year horizon GWP to implement the 6-gas standard embedded in the United Nations Framework Convention on Climate Change (UNFCCC). ${ }^{83}$ According to the IPCC itself, however, there is "no scientific argument for selecting 100 years compared with other choices" and "the choice of time horizon is a value judgement since it depends on the relative weight assigned to effects at different times." 84

This concept of $\mathrm{CO}_{2 \mathrm{e}}$, based on GWP, has several limitations. First, there is no unique value of $\mathrm{CO}_{2 \mathrm{e}}$ for any basket of emissions of multiple GHGs. ${ }^{85}$ Rather, one can only specify a value for $\mathrm{CO}_{2 \mathrm{e}}$

80. David S. Schimel, The Science of Climate Change, Contribution of Working Group I to the Second Assessment Report of the IPCC, in Climate Change 1995: The Science of Climate Change 22 (J.T. Houghton et al. eds., 1996).

81. Max K. Wallis \& Nigel J. D. Lucas, Economic Global Warming Potentials, 18 InT'L. J. ENERGy Rsch. 57, 57 (1994).

82. Gunnar Myhre et. al., Anthropogenic and Natural Radiative Forcing, Contribution of Working Group I to the Fifth Assessment Report of the Intergovernmental Panel on Climate Change, in Climate Change 2013: The Physical SCIENCE Basis 710 (Thomas F. Stocker et. al., eds. 2013).

83. See Kyoto Protocol to the United Nations Framework Convention on Climate Change art. 5, Dec. 11, 1997.

84. Myhre et al., supra note 82, at 711-12.

85. See generally Steven J. Smith \& M. L. Wigley, Global Warming Potentials: 1. Climatic Implications of Emissions Reductions, 44 Climatic Change 445 (2000). 
over a specified time horizon. Likewise, the concept of $\mathrm{CO}_{2 \mathrm{e}}$, at least if calculated using GWP as described above, cannot be applied to atmospheric concentrations at any given time or in long-term stabilization goals, since these concentrations already reflect the varying atmospheric lifetimes of GHGs. The relevant measure for atmospheric concentrations of GHGs would weight gases by the instantaneous radiative forcing only, ignoring atmospheric lifetime. In fact, there is no clearly definable set of conditions under which emissions that are equivalent in GWP terms will produce identical outcomes for even one selected aspect of climate response. ${ }^{86}$ The selection of a time horizon for GWP is also fundamentally arbitrary, with no solid basis in science. ${ }^{87}$ GWP also assumes a linear response function between radiative forcing and temperature change, which is not well-grounded in climate science. ${ }^{88}$ Finally, the GWP approach of weighting all years within the time horizon equally is inconsistent with the economic approach to future impacts, which discounts future impacts geometrically at a fixed rate. ${ }^{89}$ The SCC, for instance, is highly sensitive to the choice of this discount rate. ${ }^{90}$ The same discount rates could be used to calculate an alternative version of GWP for all GHGs. Combining an SCC or carbon price with an embedded discount rate with GWPs based on a hard-cutoff horizon is fundamentally incoherent. When considering the social cost of emissions of GHGs other than carbon dioxide, a meaningful answer cannot be derived from the existing GWPs. ${ }^{91}$

One proposal to address the arbitrary horizon issue is to apply GWPs only to the compliance period of a particular policy instrument, and then hold emitters responsible for the ongoing effects of their legacy emissions in future compliance periods. For instance, GWP with a five-year horizon could have been applied to the Kyoto Protocol's first five-year commitment period, ensuring that the contribution to total radiative forcing during that period was held constant, with the ongoing radiative forcing outside five years being counted against the emitting country's emissions budget for the

86. See generally Brian C. O'Neill, The Jury is Still Out on Global Warming Potentials, 44 Climatic Change 427, 428 (2000).

87. Jan S. Fuglestvedt et al., Metrics of Climate Change: Assessing Radiative Forcing and Emission Indices, 58 Climatic Change 267, 279 (2003).

88. Id. at 299-300.

89. Wallis \& Lucas, supra note 81.

90. See William Nordhaus, Estimates of the Social Cost of Carbon: Concepts and Results from the DICE-2013R Model and Alternative Approaches, 1 J. Ass'N ENV'T \& REs. ECONOMISTS 273, 300 (2014).

91. Alex L. Marten \& Stephen C. Newbold, Estimating the Social Cost of Non-CO2 GHG Emissions: Methane and Nitrous Oxide, 51 Energy PoL'y 957, 957 (2012). 
next commitment period. ${ }^{92}$ One problem with this approach is that it requires a long-term commitment to that paradigm to be effective. In the example used to explain the idea, the Kyoto Protocol, a second commitment period never entered force, rendering any carryover of radiative forcing from emissions in the first commitment period irrelevant. In theory, the parties to Kyoto could have incorporated the ongoing impacts of their prior emissions into the Nationally Determined Contributions (NDCs) under the Paris Agreement, but this does not seem plausible given deep structural dissimilarities between the two agreements. More generally, given the volatility of political coalitions and policy regimes, it seems unwise to adopt an approach so dependent on long-term commitment for its basic validity. It is also unclear how this approach would translate into terms compatible with the carbon price equivalent paradigm.

The global temperature change potential (GTP), a related measure used by the IPCC, is the ratio of the change in global mean surface temperature for a specified future year induced by one kilogram of GHG relative to that from one kilogram of carbon dioxide. ${ }^{93}$ GTP shares the time-horizon aspect of GWP, but GWP tends to give greater weight to short-lived GHGs by weighting all years within the horizon equally, rather than focusing on the terminal year. ${ }^{94}$ Both GWP and GTP can be treated as a special case of a more robust measure, global damage potential. Global damage potential is based on the sum of time-discounted impacts of climate change out to infinity. GWP can be thought of as a method of calculating global damage potential that assumes "(1) a finite time horizon, (2) a zero discount rate, (3) constant atmospheric concentrations, and (4) impacts that are proportional to radiative forcing." ${ }^{95}$ Calculating global damage potential without some set of simplifying assumptions may not be feasible for policy purposes, since it requires summing damages over all future time increments and discounting each time segment at the appropriate rate for the GHG being assessed and carbon dioxide in order to calculate the relevant ratio. ${ }^{96}$

Potential non-linearities in both the temperature response to marginal radiative forcing and the economic damage due to rising

92. O'Neill, supra note 86, at 438.

93. Katsumasa Tanaka et al., Policy Update: Multicomponent Climate Policy: Why Do Emission Metrics Matter?, 1 Carbon Mgmt. 191, 193 (2010).

94. Stocker et. al., eds., supra note 82, at 58.

95. Richard S. J. Tol et al., A Unifying Framework for Metrics for Aggregating the Climate Effect of Different Emissions, 7 EnvtL. Res. LetTers 1, 1 (2012).

96. Id. at 7. 
temperatures mean that any such estimate would need to rely on complex economic and climatic models and would produce estimates that are uncertain, volatile, and opaque to non-technical users. ${ }^{97}$ This highlights a tradeoff confronted in selecting a metric for aggregating the impact of GHG emissions: more economically efficient (if accurate) metrics based on the costs of climate change also tend to be more complex and uncertain. ${ }^{98}$ Moreover, any metric that incorporates non-linear effects of radiative forcing on temperature will change over time based on accumulating stocks of GHGs, even absent changes in our scientific understanding. ${ }^{99}$ Incorporating evolving economic models to estimate costs and adjusting for updates to climate response models will only add to this volatility.

The non-uniqueness of $\mathrm{CO}_{2 \mathrm{e}}$ values based on GWP is an irreducible problem, rooted in the multiple dimensions across which GHG properties can vary. Accordingly, no single aggregate measure can fully summarize the properties of a mix of GHGs. ${ }^{100}$ Any measure proposed will allow for varying mixtures of GHGs with the same aggregate weighting that nonetheless produce significantly different climate impact patterns over time. The climate implications of any sort of $\mathrm{CO}_{2 \mathrm{e}}$ target are ambiguous, therefore, unless contributions from cumulative and short-lived GHGs are specified separately. ${ }^{101}$ Even global damage potential will produce different estimates depending on the choice of discount rate, and different dynamic impacts for mixes of gases with the same global damage potential. ${ }^{102}$

The concept of radiative forcing, however, can be used to compare the instantaneous effects of atmospheric stocks of GHGs on

97. A. S. Manne \& R. G. Richels, An Alternative Approach to Establishing Trade-Offs Among Greenhouse Gases, 41 NAture 675, 677 (2001).

98. Nathan P. Gillett \& H. Damon Matthews, Accounting for Carbon Cycle Feedbacks in a Comparison of the Global Warming Effects of Greenhouse Gases, 5 Envtl. Res. Letters 1, 1 (2010).

99. Keith Shine et al., Comparing the Climate Effect of Emissions of Short-and Long-Lived Climate Agents, 365 PhIL. Trans. R. Soc. 1903, 1912 (2007).

100. Brian C. O'Neill, Economics, Natural Science, and the Costs of Global Warming Potentials-An Editorial Comment, 58 Climatic Change 251, 255 (2003).

101. Myles R. Allen et al., New Use of Global Warming Potentials to Compare Cumulative and Short-Lived Climate Pollutants, 6 Nature Climate Change 773, 773 (2016).

102. John Reilly, Mustafa Babiker \& Monika Mayer, Mit Joint Program on the Sci. and Pol'y of Glob. Change, Rep. No. 7, Comparing Greenhouse GASES 1 (2001), https://bit.ly/33TGEFb [https://perma.cc/4STFN7V7]. 
temperature. ${ }^{103}$ The instantaneous radiative forcing of a unit mass of methane is 58 times that of carbon dioxide. The ratios for nitrous oxide and HCFC-22 are 206 and 5440, respectively. ${ }^{104}$ While radiative forcing ignores the atmospheric lifetimes of GHGs, a focus on stabilizing radiative forcing can provide a useful perspective on the climate change mitigation challenge. In particular, given that the long atmospheric lifetime of carbon dioxide requires eventually reducing net emissions to zero or negative levels in order to stabilize total radiative forcing, permanent reductions in methane and other short-lived GHGs only allow for delaying, not avoiding, permanent carbon dioxide emission reductions. ${ }^{105}$ Based on this idea, a 'mixed metric' has been proposed under which a one-off sequestration of one metric ton of carbon dioxide would offset ongoing methane emissions of 0.9 to 1.05 kilograms per year. ${ }^{106}$

Stabilizing global average temperatures at any level requires stabilizing radiative forcing, so it is valuable to be able to compare GHG stocks on equal footing in the end goal state. However, this approach abstracts away the fact that early reductions in short-lived GHGs do not contribute meaningfully to long-term climate stabilization, though they would mitigate impacts in the short-term. ${ }^{107}$ For long-term stabilization, permanently reducing emissions of short-lived GHGs is crucial, since that is what allows reducing their share of the global radiative forcing budget in the stabilization scenario. Short-horizon GWP models will entirely fail to capture this insight, instead giving early reductions of short-lived GHGs a relatively heavy weighting even if those reductions are temporary.

Of course, long-term stabilization is not the only goal of climate change mitigation policy. Short-term impacts matter too, and in economic terms they matter more. In standard economic analysis, a discount rate is applied to all delayed effects of a policy or investment decision. This is to account for opportunity costs and

103. Martin Manning \& Andy Reisinger, Broader Perspectives for Comparing Different Greenhouse Gases, 369 Phil. Transactions Royal Soc'y 1891, 1891 (2011).

104. Milind Kandlikar, Indices for Comparing Greenhouse Gas Emissions: Integrating Science and Economics, 18 ENERGY ECON. 265, 272 (1996).

105. Manning \& Reisinger, supra note 103, at 1892.

106. A. R. Lauder et al., Offsetting Methane Emissions-An Alternative to Emission Equivalence Metrics, 12 Int'L J. Greenhouse Gas Control 419, 419 (2013).

107. John P. Weyant, Francisco C. de la Chesnaye \& Geoff J. Blanford, Overview of EMF-21: Multigas Mitigation and Climate Policy, 27 Energy J. 1, 27 (2006). 
pure time preference. ${ }^{108}$ If a policy or investment will produce $\$ 1$ million of benefits in 50 years, it is only worth pursuing if the upfront costs are less than alternatives that could produce equal or greater benefits. Vigorous debate is ongoing regarding the proper size of the discount rate to be used in cost-benefit analysis for climate change mitigation, but the use of some discount rate is unavoidable, though some do argue for a discount rate as low as 0.1 or even zero. ${ }^{109}$

In any case, some value for the discount rate must already be set to determine the optimal emissions reduction path, either with a fixed target in cost-effectiveness analysis or in a more open-ended cost-benefit analysis. Once this value has been selected, and has a non-zero value, it is incoherent to use a metric like GWP that assumes that rate to be zero. Moreover, even if policymakers were to adopt a zero discount rate, there would be no justification for an arbitrary cut-off horizon at 20 years, 100 years, 500 years, or any other time, save perhaps when the sun is expected to expand and subsume the earth or the anticipated heat death of the universe. If you think it is absurd to consider the impact of present emissions on the climate in 100,000 or $100,000,000$ years, that only strengthens the case for using a non-zero but steady and geometric discount rate, not an arbitrary cutoff point when the consideration of effects drops suddenly from equal treatment with all other times to complete irrelevance. While selecting a particular discount rate will certainly generate controversy, and metric results are highly sensitive to this choice just as they are to time horizon for GWP, use of any reasonable discount rate would clearly be superior to the current rectangular integration window approach. ${ }^{110}$

Use of a geometric discount rate would not necessarily require the impractical calculations described above for full global damage potential. Recalling the assumptions needed to reduce global damage potential to GWP, eliminating the finite time horizon and zero discount rate assumption need not render the calculation infeasible, so long as the assumptions of constant background atmospheric

108. Erica L. Plambeck, Chris Hope \& John Anderson, The Model: Integrating the Science and Economics of Global Warming, 19 ENERGY ECON. 77, 85 (1997). Elsewhere, I have argued that the pure time preference component should be subtracted out of the social discount rate. But see Gabriel Weil, Individual Preferences in Policy Analysis: A Normative Framework, 50 Tex. EnvtL. L.J. 55, 63 (2020).

109. See David A. Weisbach \& Cass R. Sunstein, Climate Change and Discounting the Future: A Guide for the Perplexed, 27 Yale L. \& Pol'y Rev. 433, 440 (2009).

110. Kandlikar, supra note 104, at 279. 
concentrations and impacts that are proportional to radiative forcing are retained. This change requires no new scientific understanding, only selection of a discount rate. Even the mathematical complexity introduced is minor. This is actually fairly close to the original proposal for a global warming potential index. ${ }^{111}$ Wallis and Lucas formalized this proposed metric, calling it the discounted greenhouse coefficient (DGC), and showed that it captured rates of temperature change far better than GWP. ${ }^{112}$ This approach can still be criticized for presuming "that the economic evaluations of radiative forcing in successive periods will decline at exactly the discount rate." ${ }^{113}$ However, assuming a linear relationship between radiative forcing and climate impacts is unlikely to significantly distort a metric for comparing short-lived GHGs to carbon dioxide, ${ }^{114}$ and is in any case probably necessary for the calculation to be feasible and avoid introducing substantial model uncertainty. ${ }^{115}$ Moreover, this assumption would allow the index to be relatively stable over time, only fluctuating in response to changes in the scientific understanding of the relative radiative forcing and atmospheric lifetimes of gas, but not updates to complex climate models or atmospheric GHG concentrations. While this approach does not solve all the problems with GWP, it does seem to be a clear improvement over the current undiscounted fixed-horizon model.

One defense of GWPs casts the ambiguity with regard to their meaning as a virtue, providing both scientists and policymakers with needed flexibility. ${ }^{116}$ This runs counter to the more common bases for preferring GWP to its alternatives, its simplicity and relative stability. It is also far from clear that the form of flexibility that GWP provides is optimal, since arguably no integration window can fully capture what policymakers care about. Moreover, there is reason to be skeptical that policymakers are actually making use of this flexibility, rather than treating $\mathrm{CO}_{2 \mathrm{e}}$ estimates that incorporate 100year horizon GWP values as authoritative. Shackley and Wynne also argue that by making explicit the "arbitrary" time horizon, GWP foregrounds the inevitable policy judgments in comparing

111. Daniel A. Lashof \& Dilip R. Ahuja, Relative Contributions of Greenhouse Gas Emissions to Global Warming, 344 NATURE 529, 529 (1990).

112. Wallis \& Lucas, supra note 81, at 61.

113. Richard Eckhaus, Comparing the Effects of Greenhouse Gas Emissions on Global Warming, 13 ENERGY J. 25, 27 (1992).

114. Richard Schmalense, Comparing Greenhouse Gases for Policy Purposes, 14 ENERGy J. 245, 253 (1993).

115. Gillet \& Matthews, supra note 98 , at 1.

116. Simon Shackley \& Brian Wynne, Global Warming Potentials: Ambiguity or Precision as an Aid to Policy?, 8 Climate Res. 89, 99 (1997). 
GHGs and allows policymakers flexibility to select time horizons best suited to their purposes rather than using a single metric that relies on complex modeling and assumptions imposed by the scientific community. ${ }^{117}$ While this argument could plausibly justify refraining from using climate models to incorporate non-linear radiative forcing impacts, it cannot provide a sufficient justification for entirely rejecting the concept of geometric discounting in favor of the sudden drop-off GWP approach. Similar flexibility for policymakers could be provided by calculating DGC with multiple potential discount rates and letting policymakers choose which to use, consistent with their broader approach to discounting for the harms of climate change. Indeed, this was precisely the procedure used by the Obama administration's interagency working group on the SCC, which offered SCC estimates using discount rates of 2.5 percent, 3 percent, and 5 percent for use in agency Regulatory Impact Assessments. ${ }^{118}$ Shackley and Wynne's primary criticism of the discounting approach is that it does not satisfy critics who would prefer a metric that employs modeling to fully capture the marginal costs of emissions, but they provide no persuasive argument for actually preferring the dominant GWP model. ${ }^{119}$ Their arguments against incorporating complex and ever-evolving climate models into GHG comparison metrics are fairly compelling but logically support DGC just as much as GWP.

Brian O'Neill, a GWP critic, concedes that the argument against entangling science and economics "is well founded in principle: ideally, if a purely physically-based index can perfectly equate environmental impacts, its use will produce a least-cost mix of reductions for meeting an objective based on limiting those impacts. ${ }^{120}$ Incorporating economic considerations into the index itself is not necessary." 121 However, he goes on to argue that "in practice, there are substantial deviations from the ideal case. Under these conditions, the science cannot be separated from the economics, and the problem of deriving the optimal value of the index must be solved by treating the economics and the science simultaneously." 122 That is, GWPs have not actually succeeded in

117. Id. at 93 .

118. Interagency Working Group on Social Cost of Carbon, Technical Support Document: Social Cost of Carbon for Regulatory Impact Analysis Under Executive Order 12866 (2010), https://bit.ly/3lvU6Vm [https:/ /perma.cc/F8D4-HBD2].

119. Shackley \& Wynne, supra note 116, at 94.

120. O'Neill, supra note 100, at 252.

121. $I d$.

122. Id. 
avoiding introduction of economic considerations, but in seeking to do so, they have embedded implausible economic ideas into a purportedly physical metric.

The other principal defense of GWPs is that, even if they are not the correct measure of the relative impact of GHGs, the cost of relying upon them is low. A number of efforts have been made to quantify the economic costs of relying on the GWP metric to guide policy. ${ }^{123}$ These studies find that using GWPs to guide policy tends to increase global mitigation costs by $2-3.8$ percent due mostly to overinvestment in methane emissions abatement and underinvestment in reducing nitrous oxide emissions. ${ }^{124}$ This is compared to an 11-45 percent increase in mitigation costs if policy relied only on reducing carbon dioxide emissions and ignored all other GHGs. ${ }^{125}$ Most of the two to four percent incremental costs savings from more economically sensible weighting of GHG potencies can be captured via relatively simple metrics that incorporate policy-based discount factors, but not scientifically controversial threshold effects or complex and unwieldy non-linear effects. ${ }^{126}$

A few conclusions can be reasonably drawn from this work. First, there are substantial risks associated with embedding uncertain cost and climate-response projections into GHG comparison indices. Unless and until there is greater consensus among experts in the climate and economic modeling communities, researchers should be cautious about promulgating ostensibly authoritative metrics that rely on highly contestable modeling assumptions. Second, the potential economic and environmental benefits of improved metrics are non-trivial and worth pursuing. While the prevailing estimates for efficiency gains are relatively small in percentage terms, they still represent about 10-20 percent of the efficiency gains from a multi-gas mitigation strategy relative to a carbon dioxide-only strategy. ${ }^{127}$ They are also fairly large in absolute terms, representing up to around $\$ 100$ billion per year. ${ }^{128}$

123. Manne \& Richels, supra note 97, at 675; Asbjørn Aaheim et al., Costs Savings of a Flexible Multi-Gas Climate Policy, 27 ENERgy J. 485, 485 (2006); Daniel Johansson et al., The Cost of Using Global Warming Potentials: Analysing the Trade Off Between CO2, CH4 and N2O, 77 Climatic Change 291, 291 (2006); O'Neill, supra note 100, at 255.

124. Aaheim et al., supra note 123, at 485; Reilly et al, supra note 102, at 17.

125. Aaheim et al., supra note 123, at 485; Johansson et al, supra note 123 , at 300. 256.

126. Johansson et al, supra note 123 , at 303 ; see O'Neill, supra note 100 , at

127. Aaheim et al., supra note 123 , at 485 ; Johansson et al, supra note 123 , at 291.

128. O'Neill, supra note 100, at 256. 
Moreover, none of the drawbacks associated with advanced metrics seem to apply to the more modest adjustment of applying infinite horizon discount rates, as in DGC, instead of the fixed horizon rectangular integration currently used to calculate GWPs. While researchers may be reluctant to prescribe a discount rate in the metrics they provide to policymakers, providing metrics that use a range of plausible discount rates is a clear improvement over the horizon approach, without any substantial increase in estimate uncertainty.

In implementing the carbon price equivalent approach, policymakers should weight gases using DGC estimates. DGC is a clear improvement of GWP and should be preferred to global damage potential in order to make the problem tractable and the results less dependent on contestable modeling assumptions. The discount rate embedded in the DGC estimate should be consistent with the rate used to set policy goals and assess the costs and benefits of mitigation policies. For a country acting unilaterally to border adjust an economy-wide GHG price, the discount rate embedded in that country's carbon price should be used both to determine the relative price of other GHGs and to calculate the $\mathrm{CO}_{2 \mathrm{e}}$ of foreign emissions and determine proper GHG price equivalents. In the nearterm, the WTO should generally accept good faith efforts to calculate $\mathrm{CO}_{2 \mathrm{e}}$ using a chosen discount rate, just as it should approve good faith carbon price equivalent estimates. As the carbon price equivalent approach becomes institutionalized, it would be helpful for the WTO, IPCC, or another multilateral institution to designate a discount rate to be used in $\mathrm{CO}_{2 \mathrm{e}}$ and $\mathrm{GHG}$ price equivalent calculations.

\section{Normative Considerations}

\section{A. Fairness}

One key advantage of the carbon price equivalent approach is that it is consistent with a basic normative principle: Anywhere in the world, actors who generate negative externalities should be responsible for paying their full social cost. However, in two other respects, the approach may be said to fall short. First, it would only apply prospectively. This may be unfair to actors who have less responsibility for the historic emissions that built up the existing stock of GHGs in the atmosphere. Second, the carbon price equivalent approach says nothing about what is to be done with any revenues raised from carbon pricing for those countries that adopt it. The countries and people who bear the greatest costs from cli- 
mate change impacts will not generally be the same as those who continue to emit in large quantities even after implementation of an economy-wide carbon price or equivalent set of policies. In tort law, damage awards serve both to deter tortious activities and to compensate the victims of those activities. ${ }^{129}$ If a carbon price equivalent regime were successful on its own terms, it would only serve the former function.

A related critique is that the bulk of the emissions reduction burden would be borne by countries with relatively high elasticities of demand for carbon-intensive activities. This is particularly problematic if countries retain the revenues raised by carbon taxes, capand-trade auctions, or other interventions. Countries with a lot of low-elasticity carbon-intensive activities could merely collect the carbon tax, having little actual effect on emissions. Alternatively, they could impose relatively lax command and control regulations that would achieve the relatively modest required emissions reductions.

Both of these concerns could potentially be addressed by requiring countries to remit funds raised from their carbon pricing schemes (or that would have been raised if the country adopted economy-wide carbon pricing as their primary mitigation tool) to a global fund. Revenues could then be distributed on the basis of both-relative lack of-historic responsibility for climate change and-relatively high-vulnerability to climate impacts. However, it may be infeasible to impose such a transfer regime. ${ }^{130}$ The primary purpose of the carbon price equivalent metric is to facilitate coercive climate diplomacy to get a robust climate change mitigation regime off the ground. The countries that are least vulnerable to climate change impacts and have the lowest demand elasticities for carbon-intensive activities are likely to be the most reluctant to adopt ambitious GHG emissions reduction policies. Thus, seeking to address these legitimate fairness concerns may make it more difficult to achieve the primary objective of stabilizing atmospheric GHG concentrations at a tolerable level.

Ultimately, these normative limitations are a symptom of the very problem that the carbon price equivalent metric is designed to help solve. Namely, our existing political institutions are illequipped to induce concerted global action to solve global commons problems that require countries to bear large costs to produce

129. William M. Landes \& Richard A. Posner, The Economic StrucTURE OF TORT LAW, 7-9 (1987).

130. Posner \& Sunstein, supra note 13 , at 80. 
benefits that mostly accrue to foreigners. ${ }^{131}$ Those countries that are likely to experience the smallest negative net impacts from climate change are precisely those that will be most difficult to coerce into ambitious mitigation actions. This makes it implausible that these countries would be willing to both adopt stringent emissions policies and offer compensation for the marginal impacts of the GHGs they continue to emit to the countries hardest hit by climate change.

It is somewhat more plausible that advanced industrialized countries can be persuaded to offer some compensation to developing countries for their outsized contributions to the existing stock of atmospheric GHGs. To the extent such compensation is otherwise feasible, the carbon price equivalent mechanism, which is purely forward-looking, does not present any barrier to it. Thus, to the extent that the carbon price equivalent mechanism can be said to condone unjust outcomes, these injustices are deeply embedded in the structure of geopolitics. Perhaps a politically unconstrained sovereign global climate authority could produce a more just allocation of benefits and burdens, but the carbon price equivalent mechanism must be judged against plausible alternatives. ${ }^{132}$

\section{B. Efficiency}

The principle that everyone should have to pay the full social cost of their GHG emissions-intensive activities also maps neatly onto the standard economic prescription for addressing negative externalities. A negative externality like the GHG emissions from burning fossil fuels drives a wedge between the marginal social cost and the marginal private cost of production. ${ }^{133}$ Since competitive markets will tend to equalize marginal private cost and marginal private benefit, negative externalities produce a market equilibrium quantity that is greater than the social optimum. A Pigouvian tax internalizes the negative externality by charging producers the difference between the marginal social cost and the marginal private cost, thus moving the equilibrium to a quantity that equalizes marginal social cost and marginal social benefit. ${ }^{134}$

131. See Weil, supra note 5, at 929.

132. For a detailed discussion of the possible role of a supranational climate change mitigation authority, see Weil, supra note 5, at 960-63.

133. See Emma Hutchinson, Principles of Microeconomics, Topic 5: Externalities (2017) (ebook).

134. See William J. Baumol, On Taxation and the Control of Externalities, 62 Am. Econ. Rev. 307, 311 (1972). 
This basic logic of externality pricing was called into some doubt by Ronald Coase's seminal paper, The Problem of Social Cost. ${ }^{135}$ Coase argued that, absent transaction costs, private parties will bargain to produce an efficient distribution of resources, regardless of the initial allocation. Coase also emphasized the reciprocal nature of externalities, conceptualizing them in terms of a conflict of interests between two parties rather than cases of one party harming a second, innocent party. ${ }^{136}$ Since transaction costs are important in practice, Coase concludes that legal entitlements should be allocated so as to approximate the outcome that frictionless bargaining would produce. ${ }^{137}$ In other words, responsibility for the externality should be placed upon the least-cost avoider of harm. In some cases, Coase illustrates that the least-cost avoider is the party that might ordinarily be treated as the injured party. ${ }^{138}$

In the climate context, there is some margin on which the least cost avoiders are those in a position to adapt to the consequences of climate change. Before the Industrial Revolution, the marginal cost of emissions abatement below the already very low prevailing levels was almost certainly higher than the marginal cost of adapting to any climate impact from those emissions. Even today, some abatement measures (e.g., allowing a hospital to go without electricity instead of using its carbon-intensive backup generator during an electricity grid malfunction) would not pass a cost-benefit test. Those harmed by the GHG emissions from a hospital's backup generators are very likely to be lower cost avoiders than the hospital, which would have to let some of its patients die to avoid a relatively small incremental increase in warming. This is just another way of saying that the price of GHG emissions should not be infinite and that potential adaptation measures should be accounted for when calculating the optimal abatement path. Given the globally diffuse nature of GHG emissions externalities, the best we can do to approximate the efficient outcome is to conduct a careful cost-benefit analysis and determine the price or quantity of emissions at which the marginal cost of abatement equals the marginal social costs (after accounting for adaptation measures that may lower this cost). Thus, regardless of the broader merits of the Coasian critique of

135. See generally Ronald Coase, The Problem of Social Cost, 3 J.L. \& Econ. 1 (1960).

136. See id. at 38.

137. See id. at 16 .

138. Id. at 13 . 
externality pricing, requiring emitters of GHG to pay their full net social cost is the efficiency-promoting approach. ${ }^{139}$

There is substantial uncertainty regarding the optimal path of both aggregate $\mathrm{GHG}$ emissions and carbon prices. ${ }^{140}$ Uncertainty and distributed knowledge regarding the costs of adaptation are one reason for this. ${ }^{141}$ Others include imperfect scientific understanding of climate feedback effects, the difficulty of forecasting technological progress, and unpredictable secondary social effects of climate change. ${ }^{142}$ Given that prevailing carbon price equivalents are well below the marginal social cost of GHG emissions - and given the difficulty of coordinating a global response to climate change-there is little risk that the carbon price equivalent approach will lead to too much internalization of $\mathrm{GHG}$ emissions externalities. $^{143}$

Bracketing the question of how quickly and deeply we should strive to reduce GHG emissions, the carbon price equivalent approach promotes a cost-effective allocation of emissions abatement. Most directly, it geographically distributes the obligation to reduce GHG emissions to those jurisdictions where the marginal cost of emissions abatement is lowest. If every country achieves the same carbon price equivalent, as the approach is designed to facilitate, then the geographic distribution of emissions abatement would be maximally cost-effective, at least across countries.

The distribution of emissions abatement across economic sectors, subnational geographies, and other dimensions is largely beyond the remit of a tool for climate diplomacy. However, the approach does promote efficient domestic emissions abatement in three ways. First, it establishes a safe harbor for countries that do choose to adopt economy-wide emissions pricing, which would carry through the externality-pricing logic to individual producers and consumers in line with basic economic theory. Second, even for countries that decline to adopt economy-wide carbon pricing, the carbon price equivalent approach establishes internalization of GHG emissions externalities as a normative ideal to strive for, within the constraints of domestic politics and other local circumstances. Finally, by measuring mitigation effort in terms of emis-

139. See generally Alex Bowen, Grantham Rsch. Inst. on Climate Change and the Env't, The Case for Carbon Pricing (2011), https://bit.ly/ 3ddHm2J [https://perma.cc/K765-MFKY].

140. See generally Kaufman, supra note 48.

141. $I d$.

142. $I d$.

143. See generally Katharine Ricke et. al., Country-Level Social Cost of Carbon, 8 Nature Climate Change 895 (2018). 
sions outcomes rather than mitigations costs or other indicators, the carbon price equivalent approach provides jurisdictions with an external incentive to maximize the cost-effectiveness of their domestic mitigation policies. The impact of these external influences will vary across jurisdictions, and domestic political factors will generally have a dominant role in determining the mitigation policy mix. But the carbon price equivalent approach does nudge countries toward an efficient domestic allocation of emissions abatement effort, while allowing sufficient flexibility for national policies to account for local co-benefits and accommodate domestic political imperatives.

\section{Technical, Political, and Legal Challenges}

The most obvious objection to the carbon price equivalent idea is the difficulty of obtaining credible estimates of jurisdictions' carbon price equivalents. As discussed above, this would require the use of economic models that make contestable assumptions and that have a mixed track record in terms of predictive accuracy. ${ }^{144}$ Moreover, the modeling will necessarily be a counterfactual exercise, since the jurisdictions for which the metric is needed will not have implemented economy-wide carbon pricing in an otherwise neutral policy environment. Accordingly, we will never be able to conclusively demonstrate the accuracy of carbon price equivalent estimates. Differences in modeling assumptions are likely to generate substantial controversy when large material stakes are attached to them. Even in the best case, estimating carbon price equivalents will be labor intensive and could divert resources from direct efforts to reduce GHG emissions and achieve other policy goals.

These concerns are best addressed in the context specific applications of the carbon price equivalent metric. For strategic emissions policies, it is less important that carbon price equivalent estimates be accurate and uncontroversial, for two reasons. First, countries can implement strategic emissions policies on a unilateral basis and do not need the approval of other countries. Second, so long as the methodology for estimating carbon price equivalents is transparent and bears some relation to level of mitigation effort, it will provide other countries with some incentive to increase the stringency of their domestic emissions policies. To be sure, a poorly designed estimation methodology will dampen this incentive by

144. Noah Kaufman, Michael Obeiter, \& Eleanor Krause, World Ress. Inst., Putting a Price on Carbon: Reducing Emissions 3 (2016), https:// bit.ly/3iHsoDv [https://perma.cc/MMP3-LRZA]. 
loosening the connection between other countries' effective mitigation effort and the implementing country's response function. However, the target countries need not accept the methodologies employed by the jurisdiction implementing the strategic emissions policy to be influenced by the incentives that they generate. If a carbon price equivalent estimate were only going to be used to support strategic emissions policies, different jurisdictions could adopt a range of divergent modeling approaches without substantially undermining the utility of the metric and the policy tools it supports. A less costly and less labor-intensive methodology may also be appropriate for a carbon price equivalent estimate that would only be used for strategic emissions policies.

As discussed in Part II, strategic emissions policies, whether unilateral or in coalitions, are unlikely to offer enough leverage on their own to generate robust global cooperation on climate change mitigation. Accordingly, the utility of the carbon price equivalent metric is likely to depend heavily on its deployment to support trade linkage and, more speculatively, a weak or semi-strong supranational climate authority. In either application, the carbon price equivalent metric, and estimates of it for specific jurisdictions, would need to withstand greater scrutiny.

Now consider weak trade linkage, also known as carbon tariffs or border carbon adjustments. As noted in Part II, border adjustments are a key feature of many legislation proposals for carbon pricing, and there is a strong economic and political rationale for them. However, to ensure compliance with existing international trade law, such measures must satisfy the General Agreement on Tariffs and Trade (GATT) Article XX Chapeau. ${ }^{145}$ GATT Article $\mathrm{XX}(\mathrm{g})$ provides an exemption from the GATT's tariff schedules and principles of most-favored nation and national treatment for measures "relating to the conservation of exhaustible natural resources if such measures are made effective in conjunction with restrictions on domestic production or consumption." ${ }^{46}$ The Chapeau restricts application of this and other general exemptions to "measures [that] are not applied in a manner which would constitute a means of arbitrary or unjustifiable discrimination between countries where the same conditions prevail, or a disguised restric-

145. It may be possible to structure a border adjusted carbon tax that does not violate GATT articles I, II, or III and therefore not require recourse to an article XX exception. Such a border adjusted carbon tax would not need to account for the climate change mitigation policies of exporting jurisdictions and could actually incur additional legal risk by seeking to do so.

146. General Agreement on Tariffs and Trade, art. XX(g), Oct. 30, 1947, 55 U.N.T.S. 194 [hereinafter GATT]. 
tion on international trade." The Chapeau has been interpreted by the WTO Appellate Body to prohibit attempts to coerce "specific policy decisions made by foreign governments." In the U.S.Shrimp, the original U.S. ban was struck down for requiring other countries to "adopt essentially the same policy." The Appellate Body approved a modified U.S. provision conditioning market access on "the adoption of a program comparable in effectiveness," finding that this "allows for sufficient flexibility in the application of the measure so as to avoid 'arbitrary or unjustifiable discrimination." Applying this precedent to border adjustment of a carbon tax suggests that full border adjustment would not be justified simply on the basis of the exporting countries' failure to adopt economy-wide carbon pricing_-"essentially the same policy." Border adjustments that scale with the extent to which the exporting country adopts "a program comparable in effectiveness" would, however, meet the WTO's standard. The carbon price equivalent enables quantification of program effectiveness in reducing GHG emissions, which is critical for satisfying the GATT. As we will see below, no alternative metric maps onto this standard in the same way.

The upshot of this analysis is that technical, political, and legal difficulties associated with the application of the carbon price equivalent metric to trade linkage are unavoidable, provided that countries do choose to pursue trade linkage under existing international trade law. Adjudicating between competing models will not be easy or uncontroversial. The approaches the Appellate Body is prepared to condone will not necessarily reflect the effectiveness of an economy-wide carbon price relative to other policy tools. Given the compelling need to provide countries with tools for coercive climate diplomacy and the economic efficiency rationale for border carbon adjustments, however, the case for taking on the technical, political, and legal challenges associated with carbon price equivalent estimates is quite strong.

For strong trade linkage, which cannot be made consistent with existing international trade law, reliance on the carbon price equivalent metric cannot be justified on positive legal grounds. However, the Appellate Body's Chapeau jurisprudence does represent a good model for balancing the imperatives of maintaining free and open trade with curbing cross-border externalities. Pushing through changes in international trade law to enable strong trade linkage approaches, along the lines of Nordhaus's carbon club proposal would undoubtedly be a heavy lift. However, the political challenge may be diminished somewhat by an approach that retains 
national flexibility in setting policy and focuses on outcomes of global interest. Thus, there is a strong case for incorporating the carbon price equivalent metric into a GATT-WTO framework that is modified to enable strong trade linkage in climate change mitigation policy.

Finally, consider weak and semi-strong versions of a supranational climate authority. A weak supranational climate authority would simply endorse trade sanctions and other forms of retaliation against countries that fail to meet their emissions obligations. Thus, the distinction between a weak supranational climate authority and the WTO under an international trade regime modified to accommodate strong trade linkage is fairly limited. Consequently, the same basic analysis supporting the carbon price equivalent approach applies. A semi-strong supranational climate authority, by contrast, would be empowered to set national GHG emissions targets and directly intervene when states fail to meet those targets. In this context, alternative methodologies such as equal per capita emissions allotments may be viable and would not require the laborious and controversial economic modeling associated with the carbon price equivalent. However, it is difficult to imagine countries with relatively high per capita emissions ceding sovereignty to a global authority that would impose such an allocation of the mitigation burden. The primary purpose of the carbon price equivalent metric is to enable the use of coercive climate diplomacy mechanisms that create an incentive-compatible path to preventing climate catastrophe. Without intermediate steps that are much more politically and technically feasible using a carbon price equivalent approach, it is unclear how a climate authority strong and legitimate enough to impose enforceable national per capita emissions allowances could emerge. Per capita emissions and several other alternative metrics of mitigation effort are analyzed in greater detail below.

\section{Alternative Metrics}

Given the non-trivial limitations and challenges associated with the carbon price equivalent idea, it is worth considering whether alternative metrics are preferable. In their discussion of cross-jurisdictional levels of mitigation effort, Aldy and Pizer survey several candidate metrics, including: emission levels versus historic base year, emission intensities, emission abatement-emission levels versus future emission forecast, carbon prices, energy prices and taxes, 
and costs. ${ }^{147}$ One potential metric they omit is per capita emissions. Aldy and Pizer decline to endorse a particular metric, instead supporting a multi-metric approach to international comparison. This is consistent with their overall framing of the project as operating within the pledge and review paradigm. ${ }^{148}$ However, they are rightly critical of the predominant approach of basing comparisons on emissions levels relative to a historic base year, noting emissions trends often vary for reasons that have little or nothing to do with government policy. ${ }^{149}$ They also note the potential for gaming based on selection of a reference year and potential controversy over whether the reference year should be selected so as to reward leaders for early mitigation action or support countries that still need to invest in mitigation. ${ }^{150}$

\section{A. Emissions Intensity}

Emissions intensity measures, such as tons of carbon dioxide equivalent per unit of gross domestic product, are intended to address the concern that absolute emissions limits constrain economic growth. However, Aldy and Pizer note that the approach has several significant drawbacks. First, focusing on emissions intensity allows absolute emissions to grow unless the reduction in emissions intensity exceeds the economic growth rate. ${ }^{151}$ Also,

many countries naturally experience a decline in emission intensity as their economies grow - reflecting a natural tendency towards lower energy intensity and higher efficiency. This means that a declining emission rate target could be set such that it requires no effort for compliance. Finally, some analysis has shown that emission intensity targets become more stringent if a country grows slower than expected and less stringent if it grows faster than expected. ${ }^{152}$

On a domestic level, there is some logic to the notion that since GHG emissions are bad but rising GDP is good, policies should try to lower the ratio of emissions to GDP. While falling emissions intensity is clearly preferable to rising intensity, however, its normative relevance in terms of burden sharing is suspect. Whereas GHG emissions externalities are global, a country's economic growth primarily benefits its own citizens and residents. What matters to

147. See Aldy \& Pizer, supra note 63, at 5-13.

148. See id. at 1.

149. Id. at 5-6.

150. See id. at 6.

151. Id. at 7.

152. Id. 
other countries is aggregate emissions. If anything, perhaps international comparisons of mitigation effort should require more mitigation effort from countries with more economic output. Emissions intensity also does not readily translate into a monetizable figure conducive to trade linkage.

A final concern with emissions intensity measures is that they tend, in practice, to lead to weaker emissions targets. Given anticipated economic growth, it is easier to reduce emissions intensity than aggregate emissions. This allows absolute emissions growth to be laundered into superficially impressive decreases in the emissions intensity. In principle, an emissions intensity target can be structured to be as or more ambitious than any aggregate emissions target. ${ }^{153}$ However, when emissions intensity targets have actually been proposed by China and by the George W. Bush administration in the United States, they have been weaker than plausible alternative aggregate targets. ${ }^{154}$

\section{B. Emission Abatement-Emission Levels versus Future Emission Forecast}

This option is arguably the most similar to the carbon price equivalent metric, in that both rely on comparing actual emissions to a forecast. One key difference, however, is that this formulation does not provide a monetary figure that could be used to enable trade linkage. It is also normatively questionable to entitle countries to emissions based on emissions projections. ${ }^{155}$ Emissions forecasts reflect population, economic development, resource endowments, and past and expected future policy regimes. To the extent that these forecasts reward wealthier countries or those who have and/or are expected to adopt less stringent emissions policies, that is surely problematic. The basic normative premise of the carbon price equivalent metric, by contrast, is that everyone should have to pay the full social costs of their emissions-intensive activities, regardless of the geographic location of those activities. The carbon price equivalent metric allows international law to embody this basic principle, while allowing countries the flexibility to pursue their preferred package of policies so long as their aggregate emissions fall as much as they would under an economy-wide carbon price set at a given level.

153. Id.

154. See generally Lawrence H. Goulder, Stan. Inst. for Econ. Pol'y

Rsch, U.S. Climate-Change Policy: The Bush Administration's Plan and BEYOND (2002), https://stanford.io/3dbnMUO [https://perma.cc/DG2V-VBXZ].

155. Id. 


\section{Actual Carbon Prices}

Actual carbon prices have obvious appeal as a metric for mitigation effort. Carbon prices transparently internalize some measure of the SCC and represent the marginal cost of emitting carbon dioxide from covered sources. Economic theory holds that firms and individuals will take advantage of all abatement opportunities that cost less than paying carbon price. ${ }^{156}$ However, there are two key problems with relying on actual carbon prices to measure mitigation effort. First, a nominal carbon price level may overstate a country's level of mitigation effort if it is not applied economy-wide to all sectors, all regions, and all emitters. ${ }^{157}$ Some countries may also dampen the impact of carbon pricing by decreasing other taxes or offering subsidies to companies affected by the carbon pricing, a practice known as fiscal cushioning. Conversely, it may understate a country's efforts by failing to account for non-pricing policies like renewable portfolio standards and vehicle fuel economy regulations. ${ }^{158}$ In fact, some countries have robust climate change mitigation regimes that do involve significant carbon pricing elements. ${ }^{159}$

Relying on actual carbon prices to assess mitigation effort would create a rigid structure in which only carbon pricing counts. There are two key problems with this. First, political constraints in some countries may preclude reliance on carbon pricing as the primary instrument for reducing emissions. ${ }^{160}$ A metric that only rewards actual carbon prices would deprive such countries of any incentive to adopt alternative climate change mitigation policies. Second, countries may have legitimate policy reasons for preferring to rely primarily on non-pricing policies, to reap certain co-benefits or pursue other social policy goals. ${ }^{161}$ Using actual carbon prices as the metric of mitigation effort would deprive them of the flexibility to do so. The carbon price equivalent metric is immune from these criticisms, inasmuch as it accounts for incomplete implementation of carbon pricing and the effects of non-pricing policies.

156. Id. at 9.

157. Id.

158. $I d$.

159. See Climate Change laws of the World, Grantham Rsch. Inst. on Climate Change \& the Environment \& London Sch. of Econ. \& Pol. Sci., Climate Change L. of the World database, https://bit.ly/2GJhQXn [https://perma.cc/48WS-2QZU] (last visited Sept. 6, 2019).

160. See David Victor, Global Warming Gridlock: Creating More Effective Strategies for Protecting the Planet 272 (2011).

161. See generally Alice Kaswan, Energy, Governance, and Market Mechanisms, 72 U. Miami L. Rev. 476 (2017-2018). 


\section{Implicit Carbon Prices}

Aldy and Pizer also consider implicit carbon prices that summarize the effective penalty for $\mathrm{GHG}$ emissions or subsidy for emission reductions introduced by various mitigation policies. Implicit carbon would capture a broader range of mitigation policies than explicit carbon prices but, like the carbon price equivalent, would not be directly observable. Treating policies like renewable energy subsidies as equivalent to carbon prices is also problematic, since they will tend to lower prices of carbon intensive goods and services and increase consumption, in contrast to the consumption dampening effects of a carbon tax. ${ }^{162}$ In contrast, the carbon price equivalent approach gracefully abstracts away from these issues by focusing on aggregate emissions imputing a price on that basis. Aldy and Pizer also suggest that an implicit carbon price metric might require:

constructing an economy-wide average carbon price, somehow weighting implicit and explicit carbon prices by fuel consumption throughout the value chain, in order to produce a single measure for comparison purposes. The challenge is in designing transparent, replicable methods, since some of the implicit carbon price estimates will require extensive statistical or simulation modeling analysis. $^{163}$

Instead of explicitly tracking the components of climate change mitigation policy and constructing an implicit carbon price from the bottom up, the carbon price equivalent approach would work backwards from the observed path of emissions to infer the overall stringency of mitigation policies. This would require less transparency from national governments about their policy design and enforcement and may require less onerous modeling and statistical work.

\section{E. Energy Prices and Taxes}

Aldy and Pizer also discuss energy prices as a potential proxy for mitigation effort. Unlike the carbon price equivalent, energy prices are readily observable at high frequency and influence energy supply, demand, and investment. ${ }^{164}$ High overall energy prices drive investments in energy efficiency, and high relative prices for more carbon-intensive energy sources encourage investments in low-and zero-carbon technologies. ${ }^{165}$ Like the carbon price

162. Aldy and Prizer, supra note 63, at 10.

163. Id.

164. Id. at $10-11$.

165. Id. 
equivalent, energy prices enable a net assessment of all policies, minimizing concerns that countries will offset a high headline carbon price with targeted subsidies. Energy prices also incorporate some non-price regulations that influence the cost of developing and producing energy, such as power plant emissions standards. ${ }^{166}$ However, most regulatory policies, particularly those designed to reduce energy consumption, will not be fully reflected in energy prices and may even cause energy prices to fall on net. For example, investments in energy efficiency tend to lower both GHG emissions and energy prices by reducing energy demand. ${ }^{167}$ Such policies represent a significant component of climate change mitigation efforts in many countries and should not be discounted because they do not operate by increasing energy prices. Attempts to incorporate the full effects of these policies move us back toward the implicit carbon price or carbon price equivalent approaches. Conversely, energy prices vary significantly across regions for reasons that often have little to do with climate change mitigation efforts, such as resource endowments. ${ }^{168}$ Likewise, fluctuations in energy prices are often caused by fundamental shifts in supply and demand rather than policy measures. Thus, energy prices are both over-and under-inclusive as measures of climate change mitigation effort.

\section{F. Mitigation Costs}

Aldy and Pizer claim that mitigation costs are "an intrinsically appealing metric" and "most closely aligned with economists' notion of mitigation effort." 169 This seems mistaken. A metric that rewarded countries that adopt mitigation policies with high economic costs, regardless of their actual impact on emissions, would produce at least two types of perverse incentives. First, it would remove any impetus for governments to adopt cost-effective policies. Second, it would allow countries to game the metric by labeling a wide range of costly policies with little impact on emissions as climate change mitigation policies to get credit for the costs they incur. In other words, mitigation costs are particularly vulnerable to Goodhart's Law, the notion that "when a measure becomes a target, it ceases to be a good measure." ${ }^{170}$ The carbon price equivalent approach, by contrast, is less vulnerable to this phenom-

166. Id. at 11.

167. Id.

168. Id.

169. Id. at 12 .

170. Michael Power, Counting, Control and Calculation: Reflections on Measuring and Management, 57 Hum. Rels. 765, 775 (2004). 
enon because the metric is more tightly linked to the ultimate policy goal. Moreover, despite their attraction to mitigation costs as a metric, Aldy and Pizer do express concerns about measuring mitigation costs, which are even more difficult to estimate than emissions reductions, requiring additional economic assumptions and detailed frameworks for evaluating economic changes in specific sectors and national economies. ${ }^{171}$ Thus, it seems clear that mitigation costs are dominated by the carbon price equivalent approach as a metric of mitigation effort, being both more difficult to measure and less closely tracking the emissions performance we aim to target.

\section{G. Per Capita Emissions}

Per capita GHG emissions are the most plausible alternative metric to the carbon price equivalent. Its chief advantage over the carbon price equivalent approach is that it is relatively easy to measure directly, without complex modeling and contestable assumptions. It also comports with a fairly basic principle of equality, that every person in the world should have an equal right to emit GHGs and no one should be privileged because they happen to reside in a high-emissions, advanced industrial economy. This parallels the principle embodied in the carbon price equivalent approach, that everyone should be required to pay the full social costs of their emissions-intensive activities, regardless of where they live. In neither case, of course, does the metric used ensure the underlying principle is carried through in domestic policies applied to individuals and businesses.

The carbon price equivalent metric has the added advantage of helping to ensure that emissions abatement occurs first in places where it is most cost-effective. However, this same outcome could, in principle, be achieved under a per capita metric, provided the countries are permitted to offset domestic emissions by financing emissions abatement measures in other countries where there are lower-cost opportunities. In terms of normative appeal, per capita emissions have the benefit of requiring some form of compensation from countries that continue to emit at high per capita levels because they have few low-cost abatement opportunities. On the other hand, the per capita approach implicitly endorses something akin to an individual right to some quantity of negative externality-

171. Aldy \& Pizer, supra note 63, at 12 . 
producing emissions, which lacks a firm normative foundation. ${ }^{172}$ If a global policy could be directly imposed on individuals, the everyone-pays-the- same-to-pollute principle would seem to be clearly preferable in normative terms. Given that any revenues collected via carbon pricing are unlikely to be shared globally, however, the per capita approach may offer a better approximation of the normative ideal. ${ }^{173}$

However, the per capita approach presents at least two important practical challenges. First, precisely because it would require countries that have few low-cost abatement opportunities (or just higher baseline emissions) to compensate low-emissions countries, it is unlikely to be accepted by high-emissions countries. As discussed above, equal per capita emissions allotments consistent with meeting science-based global emissions goals would require unrealistically aggressive emissions cuts in developed countries. In principle, high-emissions countries could buy offsets to equalize their net per capita emissions, but they are unlikely to be willing to engage in fiscal transfers on this scale, which would dwarf existing foreign aid budgets. ${ }^{174}$ This is for basically the same reason that sharing of actual or imputed carbon pricing revenues is unlikely under a carbon price equivalent regime. Getting countries to impose the full social cost of GHG emissions on those who engage in emissions-intensive activities and consumption is likely to be hard enough without asking them to pay compensation for those emissions that persist under the prevailing carbon price equivalent. If countries were prepared to tolerate such transfers embedded in a per capita emissions regime, they would also likely be willing to do so under a carbon price equivalent regime, negating per capita emissions' key normative advantage.

Second, differences in per capita emissions do not readily translate into quantities relevant to the most feasible and low-risk forms of coercive climate diplomacy. How should the border adjustment of a carbon tax or other domestic emissions policy scale with differences in per capita emissions? Even if such a methodology were developed, it is unlikely to pass muster under existing in-

172. Mathias Risse, Who Should Shoulder the Burden?: Global Climate Change and Common Ownership of the Earth 1, 25-29 (Harv. John F. Kennedy Sch. of Gov't, Faculty Research Working Paper Series No. RWP08-075, 2008), https://bit.ly/3ly2RP4 [https://perma.cc/PFP9-Q9S9].

173. But see Posner \& Sunstein, supra note 13, at 56.

174. See Foreign Aid: These Countries Are the Most Generous, World Econ. F., https://bit.ly/34Nr6mv [https://perma.cc/YCA8-A8S5] (last visited May 28, 2019). 
ternational trade law. ${ }^{175}$ By contrast, the difference in carbon price equivalents between jurisdictions offers a logical and legally defensible monetary value to be applied in border adjustments. In theory, strategic domestic emissions abatement policies could be indexed to average per capita emissions instead of average carbon price equivalents, but this is also not straightforward. These difficulties largely offset the key operational advantage of per capita emissions, that they can be directly measured.

The coercive climate diplomacy mechanism most compatible with a simple measure of per capita emissions is Nordhaus's Climate Club proposal. Instead of requiring that countries adopt a minimum carbon price to join the club, a revised proposal could require a maximum per capita emissions threshold for members, with flat across-the-board tariffs applied to all non-members. The binary in/out nature of Nordhaus's proposal, which is based on game theory models showing this would induce high participation, obviates the need for a monetizable scalar metric. However, countries have less direct control over their per capita emissions than they do over their implementation of an economy-wide carbon price, meaning this standard might elevate the risk that a country would unintentionally fail to meet the membership threshold in a given year and have significant across-the-board tariffs imposed on its exports. In any case, this would represent a significant modification of Nordhaus's proposal, and it is unclear whether it would be as likely to generate robust global cooperation on emissions reductions.

Less formal mechanisms of coercive climate diplomacy like non-trade issue linkage could also be feasible without a readily monetizable measure of mitigation effort. ${ }^{176}$ Finally, globally harmonized carbon pricing and a strong sovereign climate authority would both sidestep the need for a metric on national mitigation, though not the normative issues implicated in the choice between per capita emissions and the carbon price equivalent. ${ }^{177}$

175. Weil, supra note 5, at 953-55.

176. See $i d$. at $956-57$ for a more complete analysis of non-trade issue linkage.

177. Some weak forms of supranational climate authorities could still rely on a metric of comparison across jurisdictions. For instance, the weakest version would act like a supercharged WTO that authorizes trade retaliation against countries that fail to meet their emissions obligations. These obligations could be framed in terms of an emissions target based on a carbon price equivalent, a per capita allowance, or some other method. Likewise, a semi-strong climate authority could set emissions targets for countries (again, based on some metric) and allow for flexibility on how to meet those targets, only stepping in to directly regulate when countries fail to meet their targets. 
One additional consideration regarding per capita emissions is the effect that using them as the key metric for climate diplomacy would have on both population growth and outside perceptions of this growth. Unless a benchmark year fixed population figure is used, which would abandon the normative principle on which the per capita emissions metric is based, using per capita emissions to measure mitigation effort would give countries some added incentive to increase their populations. ${ }^{178}$ By codifying the notion that each additional person in the world is entitled to impose some amount of negative externalities on everyone else, it might also bolster the anti-natalist sentiments that tend to arise among some environmentalists. ${ }^{179}$ To the extent that a per capita emissions metric induces countries to promote more population growth than they otherwise would, this is both economically distortionary and somewhat counterproductive from an emissions perspective. One potential benefit is that a per capita metric would also give countries an incentive to loosen restrictions on immigration, which impose enormous economic costs, in order to facilitate domestic population growth. ${ }^{180}$ More problematically, the same incentive mechanism might induce countries to restrict emigration.

\section{CONCLUSION}

The carbon price equivalent metric outlined in this article can serve as a crucial tool supporting coercive climate diplomacy and enabling accurate border adjustment of domestic emissions policies. While the underlying mechanisms that the carbon price equivalent metric is designed to support each have their own risks and limitations, they offer paths for moving beyond the failing pledge and review model toward an incentive compatible structure for global

178. Even if a benchmark year population is used, a per capita emissions approach could still induce higher population by creating an expectation that future international agreement will allocate benefits to countries in proportion to their populations. Posner \& Sunstein, supra note 13, at 76-77.

179. See e.g., Maggie Astor, No Children Because of Climate Change? Some People Are Considering It, N.Y. Times (Feb. 5, 2018), https://nyti.ms/313qmiM [https://perma.cc/YU52-H7NF]; Travis Rieder, Science Proves Kids Are Bad for Earth. Morality Suggests We Stop Having Them, NBCNews.com (Nov. 15, 2017), https://nbcnews.to/3oQwHk8 [https://perma.cc/TTR6-77A5]; Caroline Mortimer, Having Children is One of the Most Destructive Things You Can to Do [sic] the Environment, Say Researchers, INDEPENDENT (July 12, 2017), https://bit.ly/ 30QqfPU [https://perma.cc/WS5P-9K5J]; Damian Carrington, Want to Fight Climate Change? Have Fewer Children, Guardian (July 12, 2017), https://bit.ly/ 2FfhkzF [https://perma.cc/7FCF-LFPG].

180. See generally Michael A. Clemens, Economics and Emigration: TrillionDollar Bills on the Sidewalk?, 25 J. Econ. Persps. 83 (2011). 
climate change mitigation. The most significant drawback of the metric itself is the required emissions modeling, which is labor intensive and entails contestable assumptions. However, no alternative metric is capable of filling the role of the carbon price equivalent across the full suite of coercive climate diplomacy tools. The most significant design challenge is defining an otherwise neutral policy environment to feed into the emissions model along with the specified economy-wide carbon price. The key principles for emissions modelers to follow are to avoid rewarding counterproductive policies - and discounting helpful policies_-by including them in the neutral baseline and to ensure the definition is amenable to uniform application across jurisdictions that differ widely in terms of policy approaches, resource endowments, levels of economic development, and geographies.

Other design challenges include currency conversion, the divergence between production and consumption-based emissions, emissions policy spillover effects, regulatory use of the social cost of carbon, and GHGs other than carbon dioxide. Carbon price equivalents should be converted using market exchange rates, and these conversions should be updated more frequently than the underlying carbon price equivalent estimates. Regardless of the normative locus of responsibility for GHG emissions, the basic structure and function of the carbon price equivalent metric require that it be based on emissions that physically occur within the jurisdiction (or using fuel sold in it, for international transport emissions). Spillover effects of domestic policies of extraterritorial emissions can be safely ignored in estimating carbon price equivalents and probably need to be to make the problem tractable. Since a regulatory SCC does not pervade the economy in the same way that a carbon price does, use of an SCC to set and evaluate regulatory policies should not qualify a jurisdiction for the economy-wide carbon pricing safe harbor. Finally, to maximize cost-effectiveness, the carbon price equivalent should be generalized to cover all significant anthropogenic GHGs, weighting different gases using discounted greenhouse coefficients.

The carbon price equivalent is normatively appealing, both in terms of the basic polluter-pays principle it embodies and in terms of facilitating an efficient allocation of the emissions abatement burden. The most potent normative objection to the metric-that it does not guarantee compensation for past emissions, future emissions that continue under a high carbon price, or differential vulnerabilities to climate impacts - is a consequence of the metric's inability to fundamentally transform the geopolitics of climate 
change mitigation. This is too much to demand from a metric designed to support climate diplomacy. Under the status quo, states have precious little capacity to influence the emissions behavior of other jurisdictions, relying on reputational considerations and goodwill as the primary drivers of cooperation. The measures that the carbon price equivalent supports give states leverage over each other to compel greater cooperation toward internalization of the full global social cost of GHG emissions. These measures do not and cannot fundamentally alter the relative capacity of states to exert their will in international law and diplomacy. To the extent advanced industrialized countries are prepared to offer compensation for their role in imposing enormous costs on vulnerable developing countries, I certainly salute that. The core objective of the carbon price equivalent metric developed in this article is to enable a process that limits the magnitude of those costs as much as possible going forward. 